\title{
Measurements of irradiance attenuation and estimation of aerosol single scattering albedo for biomass burning aerosols in Amazonia
}

\author{
Thomas F. Eck, ${ }^{1}$ Brent N. Holben, ${ }^{2}$ Ilya Slutsker, ${ }^{3}$ and Alberto Setzer ${ }^{4}$
}

\begin{abstract}
Investigation of the effects of biomass burning aerosols on the surface irradiance were conducted as a part of the Smoke, Clouds, and Radiation - Brazil (SCAR-B) experiment during August - September 1995. Measurements of broadband and spectral irradiance, in conjuction with measurements of aerosol physical and optical properties (optical depth, phase function, and size distribution) were made under varying conditions of aerosol loading during the SCAR-B field campaign. Estimates of aerosol single scattering albedo $\left(\omega_{n}\right)$ were made from matching of the measured irradiance values to the model computed irradiances by varying $\omega_{0}$, for observations made under cloudless conditions. Values of $\omega_{0}$, at approximately $550 \mathrm{~nm}$, estimated from this technique using broadband $400-700 \mathrm{~nm}$ irradiance measurements, ranged from approximately 0.82 to 0.94 for the dates and times of these SCAR-B measurements. Utilizing spectral irradiance data, the model retrieved values of $\omega_{0}$ decreased with increasing wavelength, with the change of $\omega_{0}$ as a function of wavelength differing on different days. Reductions in photosynthetically active radiation (PAR; $400-700 \mathrm{~nm}$ ) incident at the surface were computed to range from about 20 to $45 \%$ compared to background aerosol conditions for the 2 month biomass burning season at several locations in the southern Amazon Basin. These large reductions in incident PAR at the surface due to the heavy aerosol loadings could have implications for primary production of sensitive ecosystems. In addition, reductions of total incident solar radiation from aerosol direct radiative effects may have significant impact on reducing surface heating and increasing aerosol layer heating from absorption.
\end{abstract}

\section{Introduction}

Continuing agricultural expansion in Amazonia has led to the clearing of $6 \%$ of the closed canopy forest in the Brazilian Amazon as of 1988 [Skole and Tucker, 1993]. Biomass burning within tropical forest and cerrado (savanna) ecosystems in Brazil, associated with agricultural practices, results in large carbonaceous aerosol loadings, especially within the primary biomass burning season of August and September [Holben et al., 1996]. Prins and Menzel [1994] utilized GOES satellite data to detect active fires in a large region of southern Amazonia and found that for the peak burning season, the amount of burning detected nearly doubled in the forested regions and tripled in the cerrado regions from 1983 to 1991. Artaxo et al. [1994] have measured very large increases in fine particulates (diameter $<2.0 \mu \mathrm{m}$ ) during the

\footnotetext{
'Raytheon STX Corporation, NASA Goddard Space Flight Center, Greenbelt, Maryland

${ }^{2}$ Biospheric Sciences Branch, NASA Goddard Space Flight Center, Greenbelt, Maryland

${ }^{3}$ Science Systems and Applications Inc., NASA Goddard Space Flight Center, Greenbelt, Maryland

${ }^{4}$ Instituto de Pesquisas Espaciais, Sao Jose dos Campos, Sao Paulo, Brazil
}

Copyright 1998 by the American Geophysical Union.

Paper number 98JD00399

0148-0227/98/98JD-00399\$09.00 burning season, as a result of fires in both forest and cerrado regions, and these particles may be transported large distances [Andreae et al.,1988; Hsu et al., 1996]. Holben et al. [1996] have measured the aerosol optical thickness $\left(\tau_{\mathrm{a}}\right)$ from this biomass burning smoke to average approximately 1.0 to 1.5 at $440 \mathrm{~nm}$ for monthly means in biomass burning areas of Amazonia, versus background $\tau_{\mathrm{d}}$ values of about 0.2 at $440 \mathrm{~nm}$.

The scattering and absorption of solar radiation by biomass burning aerosols result in direct radiative forcing, which Penner et al. [1992] and Hobbs et al. [1997] have computed on a global basis. Both studies show negative forcing, although the magnitude of the computed direct forcing is much less for Hobbs et al. [1997] due to differences in the assumed and/or measured values of the aerosol optical properties. Hobbs et al. (1997) also note that for biomass burning regions of Brazil, the direct radiative forcing by these aerosols is substantial, due to the high optical depths over large regions. The solar radiation reaching Earth's surface is reduced and the energy balance in the surface-atmosphere system is modified due to scattering and absorption in the aerosol layer by carbonaceous aerosols. Robock [1991] analyzed the effects of large smoke plumes from forest fires in midlatitudes and showed that surface temperatures were reduced from $1.5^{\circ} \mathrm{C}$ to $7^{\circ} \mathrm{C}$ during the daytime but with no nighttime effects. Christopher et al. [1996] utilized satellite measurements of broadband shortwave and longwave radiances at the top of the atmosphere to study the radiative forcing of smoke aerosols over Amazonia. They found that the net radiative forcing for smoke in cloudless conditions was negative, resulting in a cooling effect. 
Similarly, Anderson et al. [1996] also computed a net cooling effect for biomass burning aerosols over cerrado regions of Brazil, based on aircraft measurements of aerosol properties and modeling.

Heavy loadings of biomass burning smoke can lead to significant reductions in the solar radiation incident at the surface. For biomass burning regions of Africa, Konzelmann et al. [1996] suggest that monthly mean differences in satellite estimated versus surface measurements of total incident solar radiation of $25-40 \%$ may be due to the radiative effects of biomass burning aerosols. Lenoble [1991] evaluated the biomass burning aerosol parameters which influence solar radiation attenuation at the surface and found that the attenuation depends mainly on the aerosol optical thickness, $\tau_{\mathrm{a}}$, and the single scattering albedo. The next parameters in order of importance were the asymmetry factor and vertical profile of the extinction coefficients. Of the two principal parameters, $\tau_{\text {, }}$ can be accurately measured from the surface by sunphotometer with uncertainties of -0.01 [Shaw, 1983], while the aerosol single scattering albedo is difficult to measure accurately.

In order to investigate the effects of biomass burning aerosols on the incident solar radiation at the surface, we collocated narrowband and broadband solar irradiance measuring instrumentation with automatic tracking Sun-sky scanning spectral radiometers, during a portion of the Smoke, Clouds, and Radiation-Brazil (SCAR-B) field campaign from August 27 to September 11, 1995 (peak burning season period), at selected sites in biomass burning regions of Mato Grosso and Rondonia, Brazil. From analysis of data collected during cloudless time periods, these measurements are utilized to infer the column integrated value of the aerosol single scattering albedo and to study the attenuation of the photosynthetically active radiation (PAR; $400-700 \mathrm{~nm}$ ) at the surface due to these aerosols.

\section{Instrumentation and Data}

The measurements which are presented in this study were made in several locations in Mato Grosso and Rondonia, Brazil. Three sites had instrumentation to measure narrowband and/or broadband irradiance, and all sites had automatic Sun and sky scanning radiometers. Narrowband and broadband irradiance measurements were made in Cuiaba $\left(15^{\circ} 33^{\prime} \mathrm{S}\right.$, $56^{\circ} 4^{\prime} \mathrm{W}$ ) in a cerrado region, and broadband only measurements were made at Potosi Mine, Rondonia (9 ${ }^{\prime \prime} 16^{\prime} \mathrm{S}, 62^{\circ} 52^{\prime} \mathrm{W}$ ), in a region of seasonal tropical forest, and at Fazenda Ipiranga in the northern Pantanal (a seasonal floodplain wetland), Mato Grosso (16 $\left.16^{\prime \prime} 3^{\prime} S, 56^{\prime \prime} 37^{\prime} \mathrm{W}\right)$. See Figure 1 for a map showing the location of instrumented sites reported in the paper. The automatic tracking Sun and sky scanning radiometers [Holben et al., 1998] made direct Sun measurements with a $0.8^{\circ}$ full field of view every $15 \mathrm{~min}$ at $339,379,437,498,669,871$, 940 , and $1021 \mathrm{~nm}$, which were used to compute aerosol optical depth at each wavelength except $940 \mathrm{~nm}$, which was used to retrieve total precipitable water in centimeters. The bandpass of the ultraviolet channels (339 and $379 \mathrm{~nm}$ ) was $2.5 \mathrm{~nm}$, while the bandpass of all other channels was $10 \mathrm{~nm}$. The sky radiance almucantar measurements at $437,669,871$, and 1021 $\mathrm{nm}$ were used to retrieve aerosol phase function and size distribution, applying the methodology of Nakajima et al.
[1996]. Remer et al. [in this issue] analyzed these almucantar inversions to develop lognormal volume size distribution smoke models which were applied in this study. The Sun-sky radiometers utilized in this study were either calibrated before and after SCAR-B at Mauna Loa Observatory (MLO) or intercalibrated with the MLO calibrated instrument in Brazil during SCAR-B. The zero air mass voltages (instrument voltage for direct normal solar flux extrapolated to the top of the atmosphere [Shaw, 1983] of all channels except $379 \mathrm{~nm}$ changed by less than $1 \%$ between MLO calibrations in May and October 1995 for the reference instrument. The $379 \mathrm{~nm}$ data were not used in this analysis.

In Cuiaba, spectral irradiance from 300 to $800 \mathrm{~nm}$ was measured at $10 \mathrm{~nm}$ intervals with $2 \mathrm{~nm}$ bandpass (Optronics OL 754 Spectroradiometer) and total and diffuse irradiance measured in six spectral bands with $10 \mathrm{~nm}$ bandpass (Yankee Environmental Systems, Multi-Filter Rotating Shadowband Radiometer (MFRSR)), in addition to broadband total irradiance (0.28-2.8 $\mu \mathrm{m}$; Eppley PSP pyranometer) and broadband PAR (0.4-0.7 $\mu \mathrm{m}$; Skye Probetech SKE-510). The Optronics spectroradiometer took measurements every $6 \mathrm{~min}$ with a scan time of approximately $3 \mathrm{~min}$ to measure irradiance from 300 to $800 \mathrm{~nm}$ in 51 wavelength intervals. The Yankee MFRSR took measurements of spectral total and diffuse irradiance at $415,500,615,670,868$, and $937 \mathrm{~nm}$ every $15 \mathrm{~s}$ and these were averaged into $1 \mathrm{~min}$ means. The broadband measurements of PAR and total irradiance were made at either 1 min or 5 min intervals depending on location. In Rondonia and the Pantanal, only broadband total and PAR irradiance measurements were made. The Optronics OL754 spectroradiometer was calibrated using a National Institute of Standards and Technology (NIST) traceable standard lamp, and the relative change in calibration from before SCAR-B to during SCAR-B ranged from $+0.5 \%$ to $-1.5 \%$ from $390 \mathrm{~nm}$ to $790 \mathrm{~nm}$. The spectral total irradiance as measured by the Optronics instrument was compared to the MFRSR instrument on August 30, 1995, in Cuiaba, and the percent difference was found to be $3.6 \%$ at $415 \mathrm{~nm},-3.8 \%$ at $500 \mathrm{~nm}$, $1.7 \%$ at $615 \mathrm{~nm}$, and $-13.3 \%$ at $670 \mathrm{~nm}$. However, the comparisons made at 415 and $615 \mathrm{~nm}$ are not direct comparisons, since the Optronics measured irradiance at 410 and $420 \mathrm{~nm}$, which were averaged to estimate $415 \mathrm{~nm}$ irradiance and, similarly, an estimate at $615 \mathrm{~nm}$ was made with 610 and $620 \mathrm{~nm}$ measurements. Optronics measurements of irradiance across the $10 \mathrm{~nm}$ range were relatively constant, differing by only about $0.5 \%$ at 610 to $620 \mathrm{~nm}$ and by about $3.0 \%$ between 410 and $420 \mathrm{~nm}$. In addition, the bandpass of the Optronics is narrower at $2 \mathrm{~nm}$, compared to $10 \mathrm{~nm}$ for the MFRSR. For all but the $670 \mathrm{~nm}$ channel, the percent differences in the comparison between Optronics and the MFRSR instrument falls within the expected accuracy of the instruments, and also given the differences in spectral bandpasses of the instruments. The Optronics spectral irradiances at $10 \mathrm{~nm}$ intervals were integrated over the 400 to $700 \mathrm{~nm}$ spectral range and compared to broadband measurements of $400-700 \mathrm{~nm}$ irradiance made by the SkyeProbetech instrument. The percent difference between these two measurements of PAR ranged from $-1.0 \%$ to $+1.5 \%$ on August 28, 1995, in Cuiaba.

The two Eppley PSP pyranometers which we utilized were calibrated by Eppley Laboratories in 1994, and in order to check their relative calibrations, we operated them side by side 


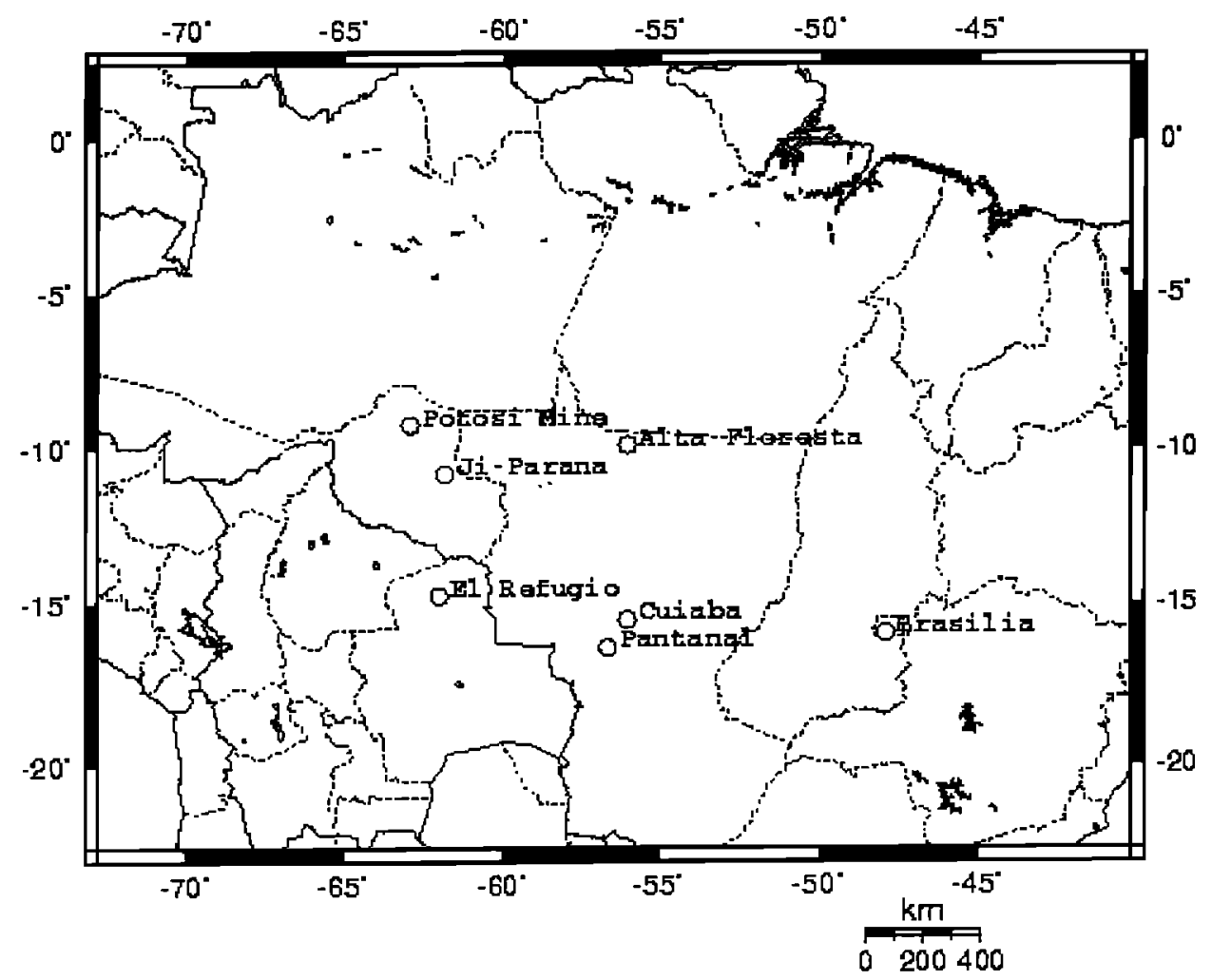

Figure 1. Map of the study region showing the location of measurement sites and the capital of Brazil, Brasilia

in Cuiaba for 5 hours on August 27, 1995. The irradiances measured by these two Eppley PSP pyranometers agreed with each other to within $1.3 \%$ or less during this time period.

In order to select cloudless conditions for analysis and comparison to computed irradiance from cloudless sky models, we utilized three cloud screening checks. First, we checked the temporal variability of the irradiance from pyranometers (1 min or 5 min intervals dependent on location), and time series of data with high-frequency temporal variation or decreasing (increasing) irradiance with decreasing (increasing) solar zenith angle were identified as influenced by the presence of cloud. Temporal variation of irradiance exceeding $2 \%$ per minute was identified as cloudy. In addition, the ratio of PAR to total irradiance is influenced by the presence of both aerosols and clouds. The PAR/total irradiance ratio is higher for cloudy conditions due to the absorption by water vapor in the near infrared, and the ratio is lower for small particle aerosols due to higher aerosol optical depths at shorter wavelengths [Pinker and Laszlo, 1992]. Therefore time series of the PAR/total irradiance ratio are sensitive to the presence of cloud and aerosols. Temporal variation of PAR/total ratio exceeding 0.003 per minute was attributed to cloud cover. The third check we employed to detect cloud contamination was the analysis of the wavelength variation of the aerosol optical depth as measured by a colocated automatic sunphotometer. For biomass burning aerosols in Brazil, the typical range of Angstrom wavelength exponent is 1.6 to 2.0 , with lower values resulting from cloud contamination, due to the large size of the cloud particles (water droplets or ice crystals). When all of these cloud screening tests were passed for at least a 1 hour interval, the data were identified as being cloudless.

\section{Cloudless Sky Irradiance Models}

We have utilized two spectral solar irradiance models in our analysis of the attenuation of solar irradiance under cloudless conditions at the surface. The first model, called SPCTRAL2 [Bird and Riordan, 1986], is a simple parameterized model of the cloudless atmosphere which Bird and Riordan adjusted to give good agreement with a rigorous radiative transfer code. The aerosol optical parameters which are used as input to the SPCTRAL2 model are the aerosol optical depth at all measured wavelengths, the asymmetry factor, and the aerosol single scattering albedo. The values of total column water vapor and aerosol optical depths as measured by the Sun-sky scanning radiometer are used as input. The asymmetry factor was determined from phase function retrievals of the Sun-sky scanning radiometer. Therefore the only aerosol parameter used in the SPCTRAL2 model which is not inferred from measurements is the single scattering albedo. Using the measured aerosol properties at the same time and location as the irradiance measurements are made, the value of single scattering albedo is varied until agreement between measured and modeled irradiance is reached. The SPCTRAL2 model contains 122 wavelengths, so irradiance estimates can be made for both narrowband ( $2 \mathrm{~nm})$ and broadband spectral regions (0.4-0.7 $\mu \mathrm{m})$.

The second model which we have used in this study is called the Second Simulation of the Satellite Signal in the Solar Spectrum (6S) [Vermote et al., 1996, 1997]. This model is a radiative transfer model which relies on the successive order of scattering method. The spectral resolution of the model is 2.5 $\mathrm{nm}$, and the aerosol layer is divided into 13 layers with a scale 
height of $2 \mathrm{~km}$. The aerosol inputs for this model are the aerosol optical depth at $550 \mathrm{~nm}$, the aerosol size distribution, and the aerosol refractive index. We have utilized the smoke aerosol models of Remer et al. [this issue] for the aerosol lognormal volume size distributions. These smoke size distributions were based on analysis of almucantar measurements made in cerrado and forest regions in Brazil. The aerosol optical depth at $550 \mathrm{~nm}$ is obtained by wavelength interpolation of the measured values at 500 and $670 \mathrm{~nm}$. The real part of the refractive index was kept constant at 1.53 or 1.40 (values representative of the probable range of the real refractive index of biomass burning aerosols [Anderson et al., 1996; Lenoble, 1991]), and the imaginary part of the refractive index is varied until the modeled irradiance is equal to the measured irradiance. Model 6S computes the phase function and extinction and scattering coefficients (and single scattering albedo) from Mie theory as an output based on the input aerosol parameters. The Mie calculations in $6 \mathrm{~S}$ assume that the scattering of solar radiation is from a mixture of homogeneous isotropic spheres, whose sizes are comparable to or larger than the wavelength. These assumptions in the Mie code of 6S are in accordance with those used in the Sunsky scanning radiometer size distribution retrieval algorithm used with almucantar observations. Measurements of smoke particle shape in Brazil during SCAR-B by Martins et al. [1996] suggest that smoke in regional hazes over Amazonia consists largely of spherical particles, and thus the use of the Mie calculations is valid.

In both models, we have input a range of different surface spectral albedo values, which were not measured at the site, in order to analyze the model sensitivity to surface albedo magnitude. For the SPCTRAL2 model, we utilized the spectral reflectance data of Deering [1989] for a bare soil and a vegetated crop canopy and for the $6 \mathrm{~S}$ model there is a set of spectral reflectance data within the model which are representative of a vegetated surface and a sandy surface [Vermote et al., 1996]. For example, at $630 \mathrm{~nm}$, the reflectance values we used in the SPCTRAL2 model were $4.3 \%$ for vegetation and $16.9 \%$ for soil, while for the $6 \mathrm{~S}$ model the values at $630 \mathrm{~nm}$ were $7.5 \%$ for vegetation and $16.3 \%$ for soil.

\section{Irradiance Measurements and Retrieval of Aerosol Single Scattering Albedo}

Figure 2 shows the aerosol optical thickness measured from direct Sun observations by the Sun-sky scanning radiometer from August 27 (day 238) through September 1, 1995 (day 243), in Cuiaba, which shows the large range in aerosol loading which occurred during this time period. These large day to day variations in $\tau_{\mathrm{a}}$ at this site are due primarily to changes in air mass trajectories, with advection from burning regions on some days and advection from regions with few fires on others [Remer et al., this issue]. The large wavelength dependence of the $\tau_{\mathrm{n}}$ for these biomass burning aerosols is evident, especially for days with the highest aerosol loadings, August 29 and 30 (days 240 and 241). The Angstrom wavelength exponent $(\alpha)$ computed from the 440 and $870 \mathrm{~nm}$ channels for these days of highest aerosol loading ranged from approximately 1.8 to 2.0 , indicative of particles with small radius. The Angstrom wavelength exponent was computed as:

$$
\alpha=\ln \left(\tau_{\mathrm{a} 1} / \tau_{\mathrm{a} 2}\right) / \ln \left(\lambda_{2} / \lambda_{1}\right)
$$

where $\lambda$ is the wavelength of the measured $\tau_{a}$ values.

In order to investigate directly the spectral attenuation of irradiance from these aerosols, we computed the ratio of spectral irradiance (measured by the Optronics instrument at 10 $\mathrm{nm}$ intervals) from the day of highest $\tau_{\mathrm{a}}$, August $30\left(\tau_{\mathrm{a} 50)}=\right.$ 2.28 ), to the day of lowest $\tau_{\mathrm{u}}$, August $28\left(\tau_{\mathrm{as}(\mathrm{x})}=0.37\right.$ ) (see Figure 2), for a cloudless time period on each day. Figure $3 \mathrm{a}$ shows the values of these irradiance ratios from 300 to $800 \mathrm{~nm}$ for the solar zenith angle range of $37.6^{\circ}$ to $44.5^{\circ}$. It is seen

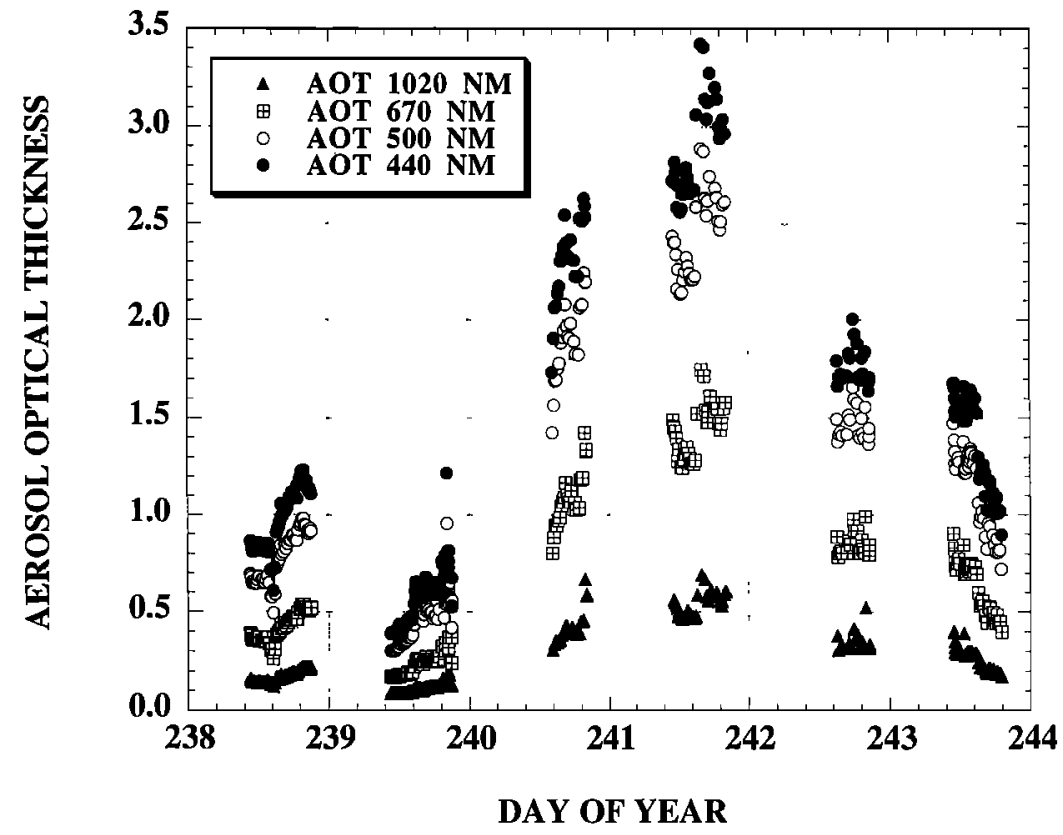

Figure 2. The aerosol optical thickness (AOT) measured at Cuiaba, Brazil, from August 27 to September 1, 1995, by the direct Sun measurements from the Sun-sky scanning spectral radiometer. 


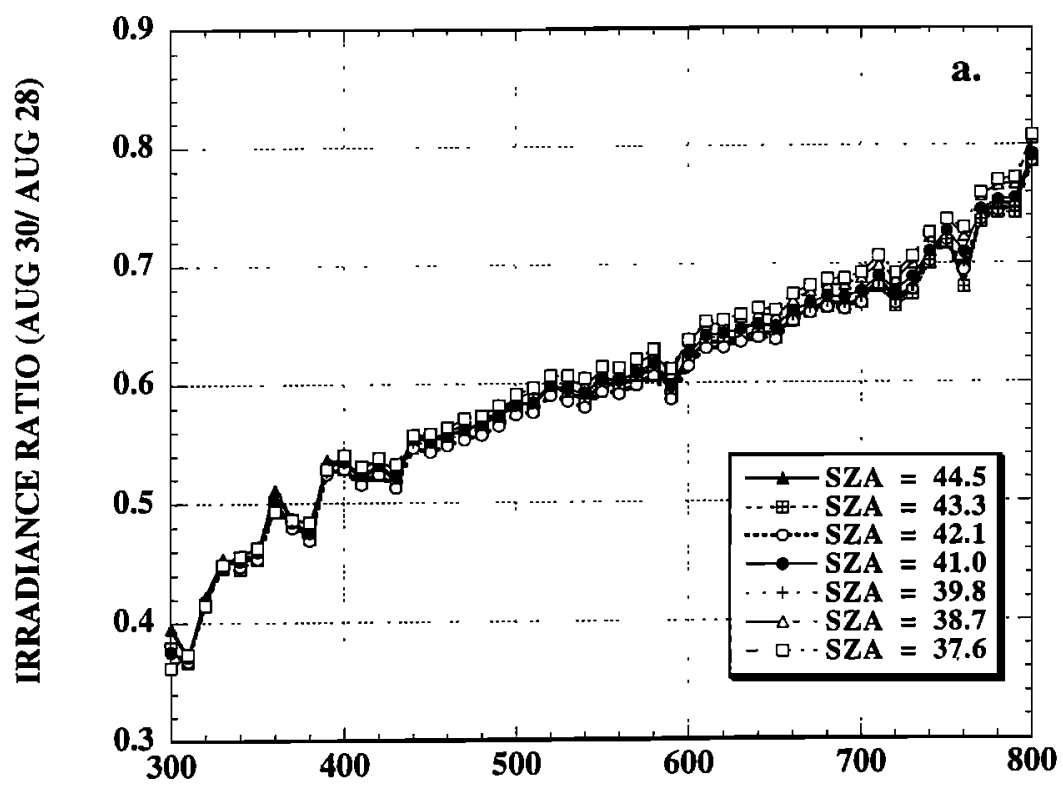

WAVELENGTH (nm)

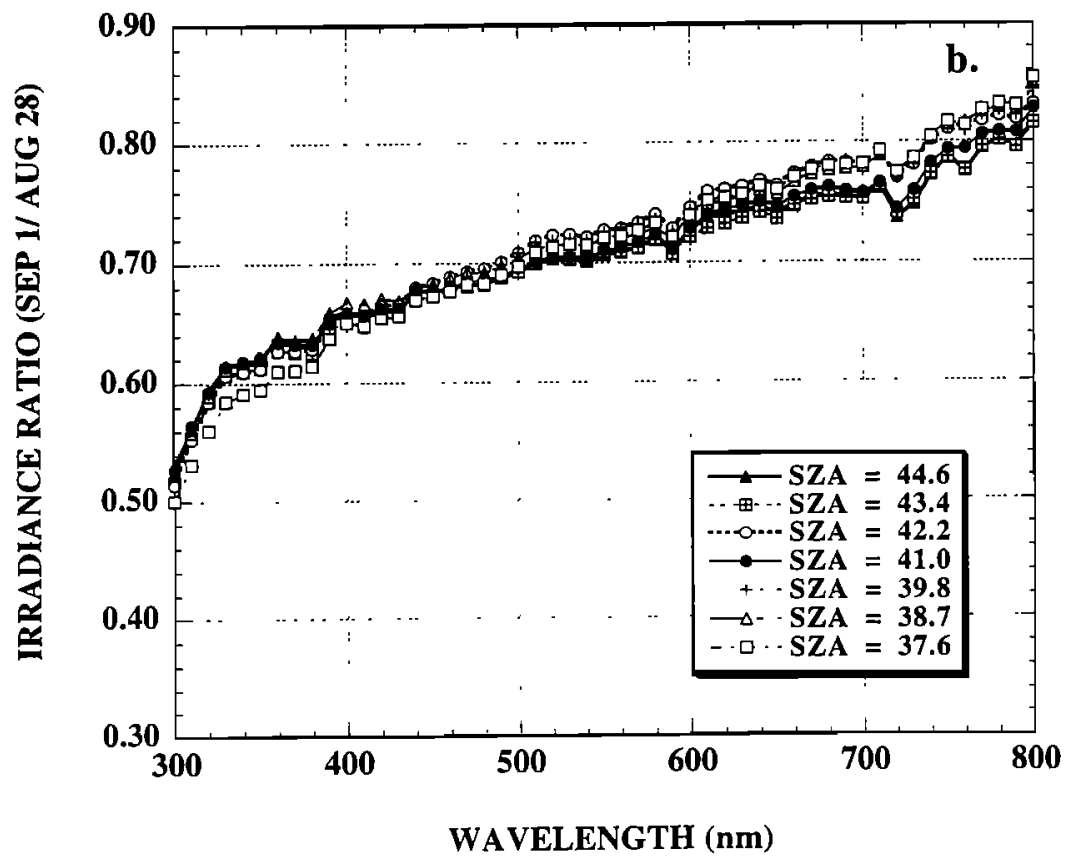

Figure 3. (a) Ratio of spectral irradiance (measured by the Optronics 754 spectroradiometer instrument at 10 $\mathrm{nm}$ intervals from 300 to $800 \mathrm{~nm}$ ) from the day of highest $\tau_{d}$, August $30,1995\left(\tau_{\mathrm{as}(\mathrm{x})}=2.28\right)$ in Cuiaba (see Figure 2), to the day of lowest $\tau_{\star}$, August $28,1995\left(\tau_{\mathrm{a} S(K)}=0.37\right)$, for a cloudless time period on each for the solar zenith angle (SZA) range of $37.6^{\circ}$ to $44.5^{\circ}(\mathrm{b})$. The irradiance ratio of September $1\left(\tau_{\text {a500 }}=1.29\right)$ to August 28 computed, with higher ratios than for the August 30/August 28 irradiance ratios since the aerosol loading is less on September 1.

that the $550 \mathrm{~nm}$ irradiance is reduced by about $40 \%$ on the hazy day relative the clear day, and that for the PAR region $(400-$ $700 \mathrm{~nm}$ ) the reduction ranges from about $47 \%$ at $400 \mathrm{~nm}$ to about $32 \%$ at $700 \mathrm{~nm}$. For a portion of the UVB region, 300$320 \mathrm{~nm}$, the irradiance reduction, comparing these 2 days, is about $63 \%$ at these solar zenith angles. These reductions would be significantly larger if compared to background values of $\tau$. $\left(\tau_{\mathrm{a} 500} \approx 0.15\right.$ [Holben et al., 1996]), since the $\tau_{\mathrm{is50}}$ on August 28 , the clear day, was 0.37 during this time period. The irradiance ratio of September $1\left(\tau_{\mathrm{i} 510}=1.29\right)$ to August 28 was also computed and is shown in Figure $3 \mathrm{~b}$. As expected, the ratios are higher than for the August 30/August 28 irradiance ratios, since the aerosol loading is less on September 1 than on August 30, but the percentage reduction in irradiance per 0.1 increment of $\tau_{\mathrm{a}}$ is greater on September 1 than on August $30\left(3.3 \%\right.$ per $0.1 \tau_{\mathrm{a} 1}$ on September 1 versus $2.2 \%$ per $0.1 \tau_{\mathrm{a}}$ at $500 \mathrm{~nm}$ on August 30). This can be accounted for by the smoke aerosol on September 1 being more strongly absorbing than 


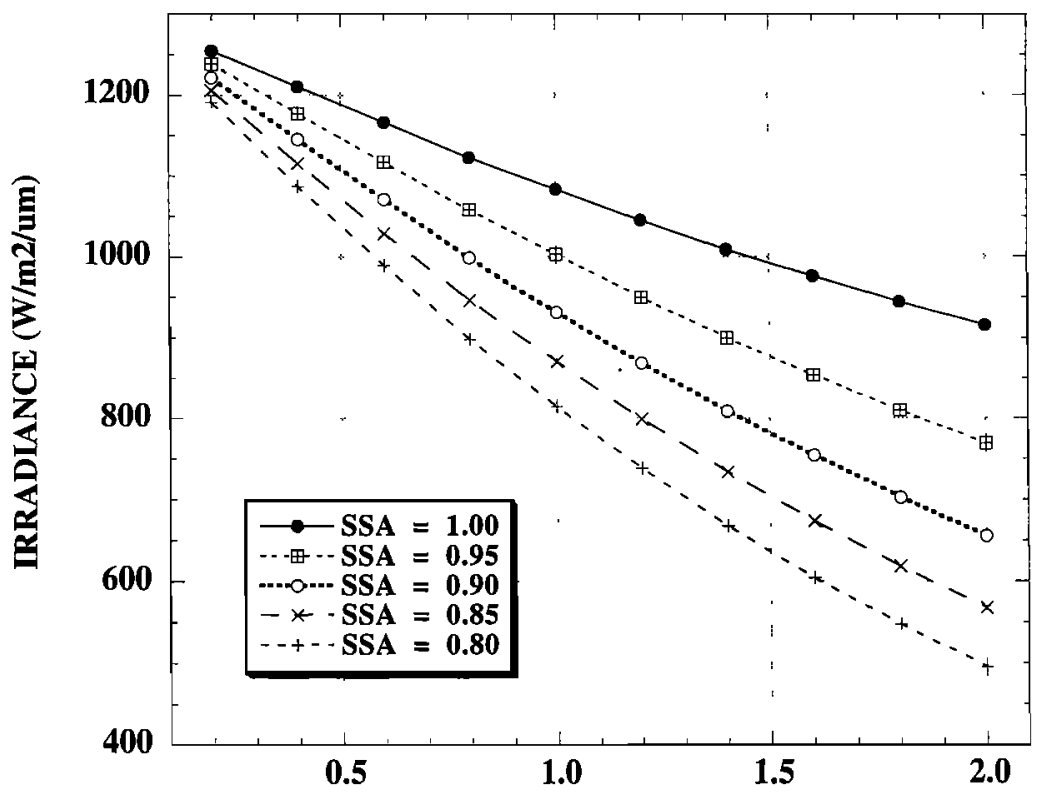

AEROSOL OPTICAL DEPTH $(550 \mathbf{~ n m})$

Figure 4. Irradiance at Earth's surface at $550 \mathrm{~nm}$ computed by the $6 \mathrm{~S}$ model at $40^{\circ}$ solar zenith angle. Computations are made for five values of single scattering albedo (SSA) from 1.0 to 0.80 , with a smoke model aerosol volume size distribution.

the aerosol on August 30. This will be investigated further in the retrieval of $\omega_{i}$ for these two cases.

The $6 \mathrm{~S}$ model was used to compute the changes in irradiance at $550 \mathrm{~nm}$, for a solar zenith angle of $40^{\circ}$, which result from both variations in aerosol optical depth and single scattering albedo (Figure 4). We utilized the cerrado smoke model lognormal size distribution of Remer et al. [this issue], with modal particle radius of $0.132 \mu \mathrm{m}$, as input to $6 \mathrm{~S}$ and fixed the real part of the imaginary refractive index at 1.53, which resulted in an asymmetry factor of 0.63 . From this analysis, we can see that the irradiance change, at Earth's surface at 550 $\mathrm{nm}$, resulting from a change in aerosol single scattering albedo from 1.0 to 0.80 , is relatively small at $\tau_{\mathrm{u}}$ of 0.2 (about $5 \%$ ), while at $\tau_{\mathrm{a}}$ of 2.0 we see a decrease in irradiance of approximately $46 \%$ from $\omega_{0}$ of 1.0 to 0.80 . Therefore for cases of moderate to high aerosol loading, measurements of solar irradiance are very sensitive to the magnitude of aerosol absorption and thus to the value of $\omega_{0}$. For example, at $\tau_{\mathrm{a}}$ of 0.80 at $550 \mathrm{~nm}$, an error in irradiance of $1 \%$ will result in approximately a 0.01 error in the retrieval of $\omega_{11}$, retrieved using the technique described in the previous section. Therefore errors in $\omega_{0}$ retrieval from this technique can be expected to range from 0.02 to 0.03 for aerosol optical thickness of 0.80 at $40^{\circ}$ solar zenith, based on our approximate irradiance measurement accuracy of 2-3\%. Errors in $\omega_{0}$ retrieval, due to irradiance measurement errors, at larger values of $\tau_{\mathrm{a}}$ will be smaller (e.g., $\omega_{0}$ error of $\sim 0.005$ per $1 \%$ irradiance measurement error at $\tau_{\mathrm{a}}=1.6$ ) and errors at lower values of $\tau_{d}$ will be larger than this (e.g., $\omega_{0}$ error of $\sim 0.02$ per $1 \%$ error in irradiance at $\tau_{\mathrm{a}}=0.4$ ) for this solar zenith angle.

We made a comparison of the spectal irradiance measured by the Optronics instrument to values computed by the two atmospheric models for a case with relatively low aerosol loading (with respect to burning season values), August 28,
1995, in Cuiaba. The observation time which we selected was 1400 GMT on August 28 with solar zenith angle of $36.3^{\circ}$, precipitable water of $1.87 \mathrm{~cm}$, and aerosol optical thickness of 0.37 at $500 \mathrm{~nm}$ and 0.14 at $670 \mathrm{~nm}$. The measured and modeled irradiances at this observation time are shown in Figure 5. For the modeled irradiances, from both the $6 \mathrm{~S}$ and SPCTRAL2 models, we assumed a constant value of single scattering albedo with wavelength of 0.94, which yielded good agreement with the measurements at most wavelengths. However, at the relatively low aerosol loadings on this day the irradiance sensitivity to the magnitude of $\omega_{0}$ is small (Figure 4). As can be seen from the irradiance plot, both models reproduce the major features of the measured irradiance from 390 to $780 \mathrm{~nm}$ with differences at most wavelenghths of $4 \%$ or less. However, both models do show larger differences from the measurements at 440 and $520 \mathrm{~nm}$. Both of these wavelengths are at regions of large gradients in the solar spectral irradiance. The discrepancy may be due to a calibration uncertainty in the Optronics instrument, a temperature dependent instrumental wavelength shift, or possibly the extraterrestrial solar flux data, since both models use the values of Neckel and Labs [1981]. We do not know which of these is the most likely cause of the discrepancy, however. It is also noted that there are large departures between the $6 \mathrm{~S}$ computed irradiances and measurements at 390 and $400 \mathrm{~nm}$. Owing to these anomalies, we will present only results of high spectral resolution analysis for $6 \mathrm{~S}$ from $410 \mathrm{~nm}$ upward and not present the results of either model at 440 and $520 \mathrm{~nm}$ in the following spectral analyses.

For two days in Cuiaba (September 1 and August 30, 1995) which had heavy smoke loading, we made spectral irradiance measurements with the Optonics instrument, which were then used to estimate spectral values of $\omega_{0}$ based on matching the modeled irradiance to measured irradiance. The results of $\omega_{0}$ 

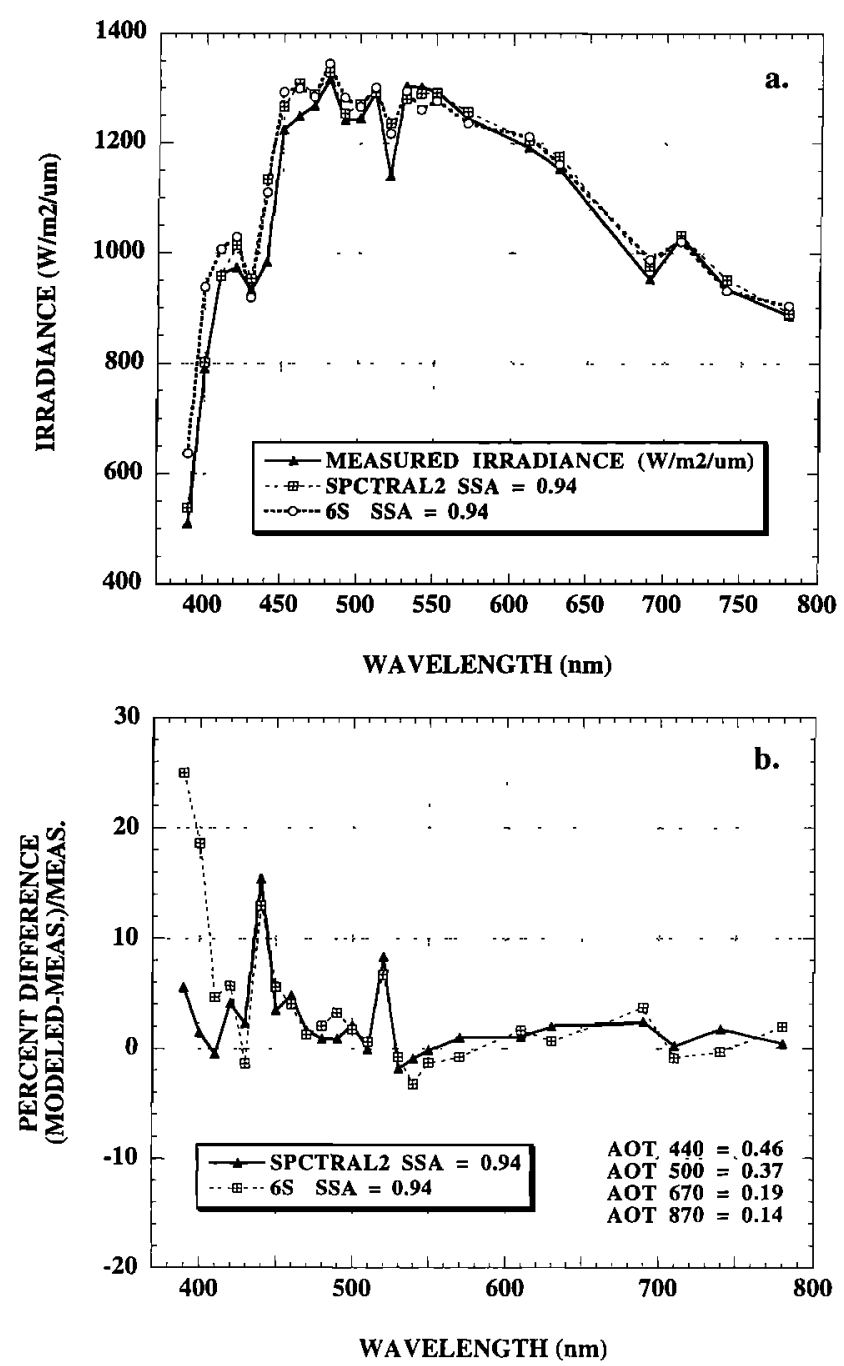

Figure 5. Spectral irradiance comparison for August 28, 1995, at 1400 GMT (solar zenith $36.3^{\circ}$ ) in Cuiaba of measured spectral irradiance from the Optronics OL 754 spectroradiometer to modeled irradiance from the SPCTRAL2 and $6 \mathrm{~S}$ models. Measured spectral $\tau$ was used as input to the models. Measured $\tau_{\mathrm{a}}$ was relatively low for this case with $\tau_{\mathrm{d} 550}=$ 0.31 .

retrievals from the Optronics measurements made on September 1, 1995, at $1330 \mathrm{GMT}$ (solar zenith angle $40.6^{\circ}$ ) in Cuiaba are given in Figure 6. There was a heavy smoke aerosol loading on this day with $\tau_{\mathrm{a}}$ at $550 \mathrm{~nm}$ of 1.06 . The value of the asymmetry factor which was used in the SPCTRAL2 model was 0.58 , based on almucantar retrievals for smoke aerosol at high $\tau_{\mathrm{a}}$. Both models retrieved $\omega_{\mathrm{v}}$ values which showed significant decreases from 400 to $740 \mathrm{~nm}$, with SPCTRAL2 showing a drop of about 0.13 over this range and $6 S$ showing a $\omega_{n}$ decrease of approximately 0.10 . The exact aerosol size distribution and real part of the refractive index (which are input parameters to the $6 \mathrm{~S}$ model) are not known for these observations, due in part (for the size distribution) to a lack of almucantar inversions, which are not successful above $\tau_{\mathrm{a}}$ of approximately 1.0 due to multiple scattering effects [Nakajima, et al., 1983]. Therefore we used two values of lognormal aerosol volume size distributions for smoke aerosol from Remer et al. [this issue] which spanned a wide range of aerosol size, with the modal radius of the aerosol at 0.132 and $0.17 \mu \mathrm{m}$. We also used two values of the real part of the refractive index, 1.53 and 1.40 , since the true value is unknown. As is shown in Figure 6a there is a range in $\omega_{0}$ of about 0.03-0.04 due to combinations of these two aerosol parameters. The retrieved $\omega_{0}$ decreases with increase in particle size and also decreases with decreases in the real part of the refractive index. Therefore differences between retrievals of $\omega_{0}$ made with the SPCTRAL2 and $6 \mathrm{~S}$ models range from about 0.05 to 0.01 for this case, dependent on the input size distribution and real refractive index utilized in the $6 \mathrm{~S}$ model. Retrieved $\omega_{0}$ values from $6 \mathrm{~S}$ as a function of surface albedo (Figure 6b) for sand albedo and vegetation albedo differed the most for the near-infrared wavelengths of 710 and $740 \mathrm{~nm}$,
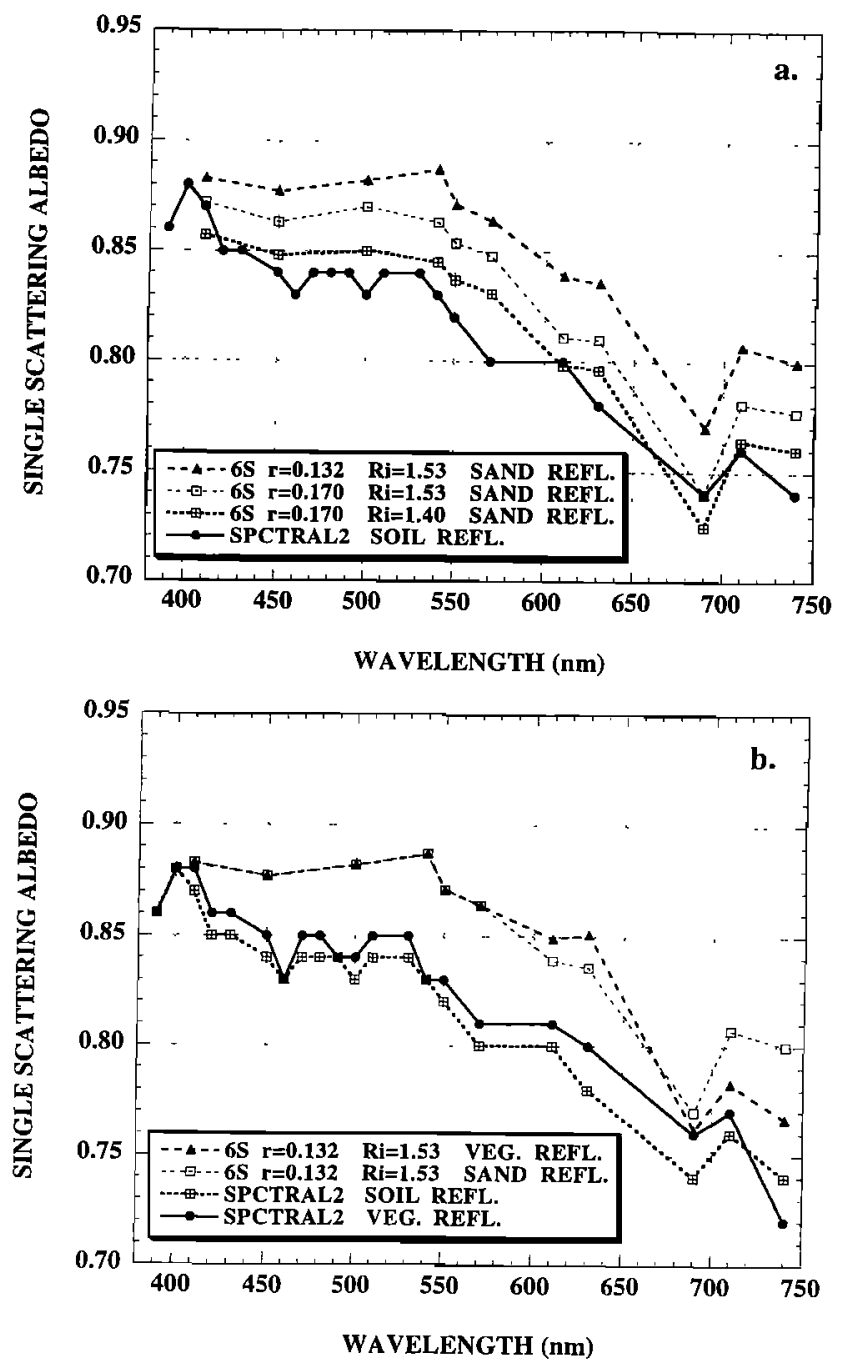

Figure 6. (a) Single scattering albedo estimates inferred from the 6S and SPCTRAL2 models for September 1, 1995, at 1330 GMT in Cuiaba, when $\tau_{2550}$ was 1.06. The solar zenith angle for this case was $40.6^{10}$. Measured $\tau_{a}$ were input to the models, and measured irradiances from the Optronics OL 754 spectroradiometer were also used in the retrievals. The particle radius (lognormal volume size distribution) was varied from 0.132 to $0.170 \mu \mathrm{m}$, and the real part of the refractive index was varied from 1.53 to 1.40 . (b) Both the $6 \mathrm{~S}$ and SPCTRAL2 models run with spectral albedo specified for a vegetation surface and for a sand surface. 

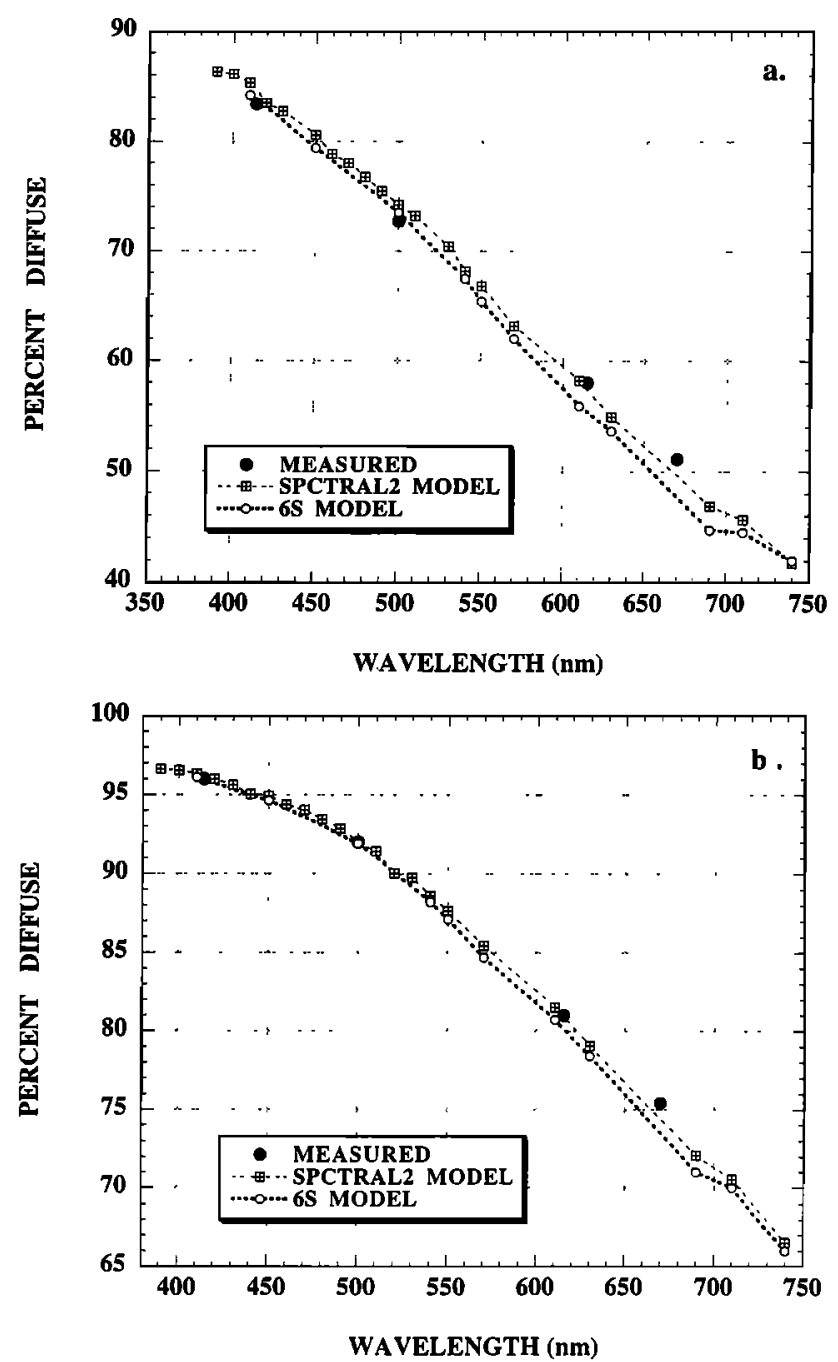

Figure 7. The computed values of the percent diffuse irradiance from the $6 \mathrm{~S}$ and SPCTRAL2 models compared with the measured values at four wavelengths from the MFRSR shadowband radiometer for (a) September 1, 1995 in Cuiaba and (b) August 30 in Cuiaba (see Figure 6 and 8, same cases).

since the vegetation albedo was approximately $50 \%$ versus about $25 \%$ for the sand albedo at these wavelengths. At other wavelengths, the differences in the albedo for the two surfaces were considerably smaller. For the SPCTRAL2 model the differences between the retrieved values of $\omega_{0}$ ranged from 0.0 to $\mathbf{0 . 0 2}$ for the two different surface spectral reflectances, soil and vegetation. Therefore both models showed only a small to moderate change of retrieved $\omega_{0}$ over the expected range of surface reflectance in the PAR wavelengths $(400-700 \mathrm{~nm})$, with larger differences in $\omega_{0}(0.03)$ due to larger surface relectance differences of $25 \%$ absolute. The computed values of the percent diffuse irradiance from the $6 S$ and SPCTRAL2 models were in very good agreement with the measured values from the MFRSR shadowband radiometer (Figure 7a), with differences of $1-3 \%$ at the four measured wavelengths.

On August 30, 1995 in Cuiaba the smoke aerosol loading was extremely high, with the $\tau_{\mathrm{a}}=1.93$ at $550 \mathrm{~nm}$ at $1332 \mathrm{GMT}$ (solar zenith angle $40.8^{\circ}$ ). On this day the wavelength variation in $\omega_{0}$ as retrieved by both models, $6 S$ and SPCTRAL2
(Figure 8a) was less than for September 1, and the difference in inferred $\omega_{0}$ between the two models was greater, ranging from about 0.03 to 0.08 , dependent on wavelength and the values of real refractive index and aerosol size distribution utilized in the $6 \mathrm{~S}$ model. It is noted that the aerosol volume size distribution models of Remer et al. [this issue] only include almucantar data analysis of cases with smoke $\tau_{\mathrm{u}}$ up to about 0.7 at $670 \mathrm{~nm}$ (due to the previously mentioned limits on the retrievals), while for this case the $\tau_{\mathrm{a}}$ at $670 \mathrm{~nm}$ was 1.35 , approximately twice as high. Therefore there may be considerable uncertainty in the aerosol volume size distribution for cases such as this with extremely high aerosol loading. Also for the SPCTRAL2 model there may be a greater uncertainty in the asymmetry parameter, since this parameter is also retieved from almucantar measurements with maximum $\tau_{\mathbf{a}}$ of approximately 0.7 at $670 \mathrm{~nm}$. Both the $6 \mathrm{~S}$ and SPCTRAL2 irradiance models also may have larger uncertainties for cases with very high $\tau_{\mathrm{a}}$ and resultant high multiple scattering due to approximations in the radiative transfer code. The sensitivity of the retrievals to change in surface spectral reflectance for soil/sand and vegetated surfaces is similar for this case (Figure $8 b$ ) as it was
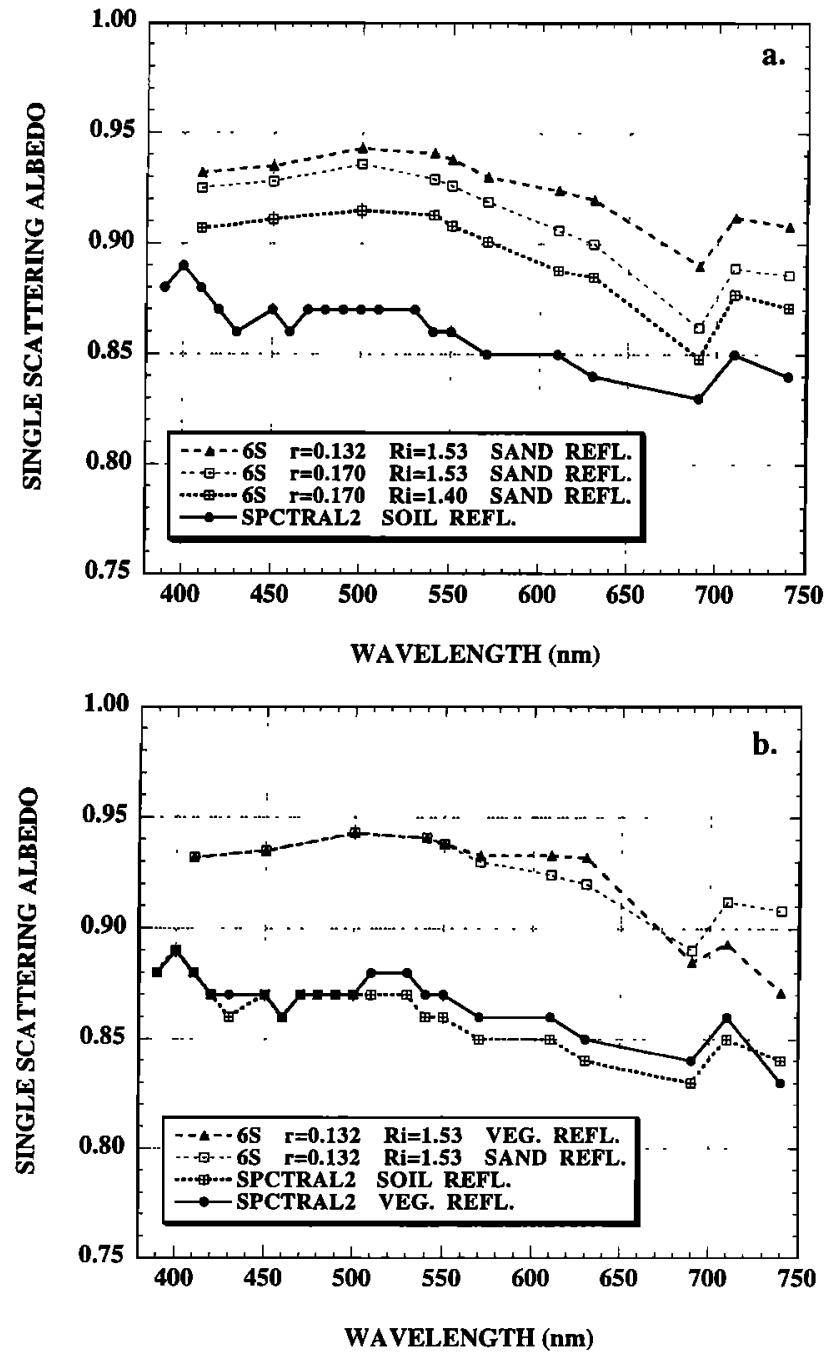

Figure 8. Same as Figure 6 but for August 30, 1995, at 1332 GMT in Cuiaba when $\tau_{\text {asso }}$ was 1.93 , significantly higher than the September 1, 1995, case shown in Figure 6. The solar zenith angle for this case was $40.8^{\circ}$. 
Table 1. Single Scattering Albedo $\left(\omega_{0}\right)$ Values Derived From Broadband PAR Irradiance Measurements Utilizing SPCTRAL2 and 6S Models, Showing the Influence of Surface Reflectance for Both Models and Variation in the Real Refractive Index $n_{r}$ for $6 S$

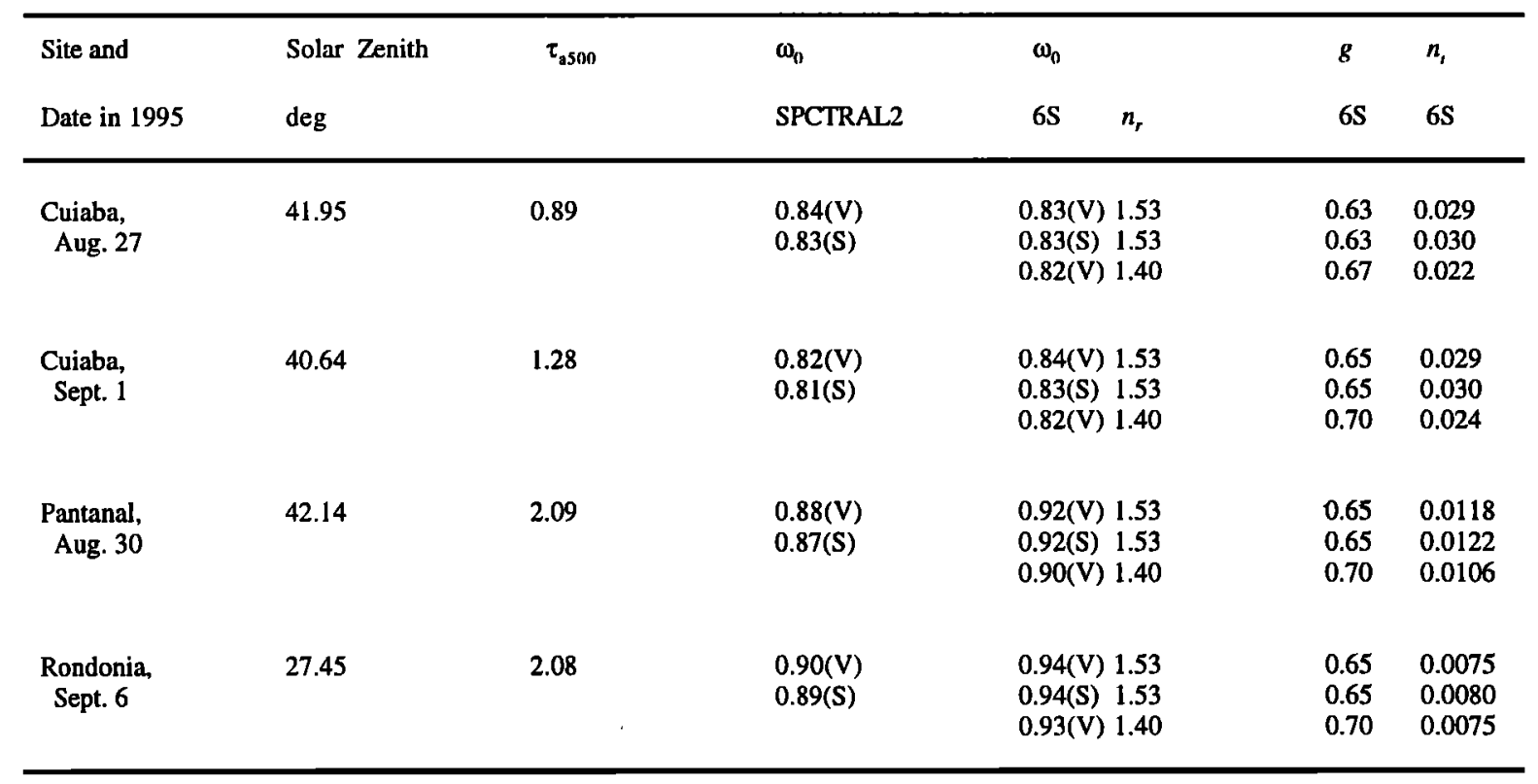

The asymmetry parameter $g$ and imaginary part of the refractive index $n_{1}$ is shown for the $6 S$ retrievals. V, vegetation; $S$, soil.

for the September 1 case (Figure 6b) Also, the spectral percentage of diffuse irradiance computed from the two models is in excellent agreement with the measurements made with the MFRSR shadowband radiometer, within about $1-2 \%$ at the four measurement wavelengths (Figure $7 \mathrm{~b}$ ).

On August 27, 1995, in Cuiaba, we did not have spectral irradiance measurements, but we did take broadband measurements of the PAR irradiance from 400 to $700 \mathrm{~nm}$. For observations taken at 1800 GMT (solar zenith angle $41.9^{\circ}$ ) both models were utilized to retrieve the $\omega_{\mathrm{n}}$. Measured values of $\tau_{\mathrm{u}}$ at $339,437,498,669$, and $871 \mathrm{~nm}$ were input to the SPCTRAL2 model, while the $\tau_{\mathrm{a}}$ at $550 \mathrm{~nm}$ was computed from interpolation to be used as input for the $6 \mathrm{~S}$ model. The retrieved value of single scattering albedo in the PAR waveband using $6 \mathrm{~S}$ was 0.83 for both sand and vegetation albedo (Table 1). This compares quite closely with the values retrieved with the SPCTRAL2 model of 0.84 assuming vegetation albedo and 0.83 assuming soil albedo. Measurements of $\omega_{10}$ made from aircraft from in situ air samples for this date and location by Reid et al. [this issue] were also in very close agreement to these values, $\omega_{0}=0.83$ from the integrating plate technique and $\omega_{n}=0.82$ from the particle soot/absorption photometer. The aerosol optical depth for this case was 0.89 at $500 \mathrm{~nm}$ and 0.47 at $670 \mathrm{~nm}$. These aerosol loadings are lower than for the previous two cases discussed, and the smoke volume size distribution model (at $\tau_{\mathrm{a}}$ $=0.6$ at $670 \mathrm{~nm}$ ) of Remer et al. [this issue] should be representative for this case, while its applicability for the other cases studied is less certain. The lognormal volume size distribution model of Remer et al. [this issue] used for this case had a volume modal radius of $0.132 \mu \mathrm{m}$, while for the other three cases in Table 1 (which have higher $\tau_{2}$ ) another smoke model of Remer et al. [this issue] with modal radius of $0.17 \mu \mathrm{m}$ was used. Analysis of ground-based measurements of aerosol size distribution at Cuiaba in 1995 by $\mathrm{Ji}$ et al. [1996] showed that the particle size increased as aerosol loading increased. Reid et al. [this issue] also report significant variability in aerosol size distributions for regional hazes in Amazonia, with volume mean radius over Rondonia (during the first week of September 1995) and the Pantanal (on August 30, 1995) about $0.03 \mu \mathrm{m}$ larger than over Cuiaba (last week of August 1995). Three other cases of $\omega_{11}$ retrieval from broadband PAR irradiance measurements are shown in Table 1. It is seen that the values of $\omega_{n}$ retrieved from the two models, $6 S$ and SPCTRAL2, diverge as $\tau_{\mathrm{a}}$ increases, with excellent to good agreement for the cases with $\tau_{\mathrm{n} 500}$ of 0.89 and 1.28, respectively, while for two cases with $\tau_{\mathrm{n} s(\mathrm{x})}=2.08$ the difference in $\omega_{6}$ is $0.02-0.05$. As discussed earlier, the differences in the retrievals between the two models is due in part to uncertainty in input parameter values to the $6 \mathrm{~S}$ model (real refractive index and volume size distribution) and also probably due to larger uncertainty in both models at very high aerosol loadings. In a related application, the computation of atmospheric backscattered radiance to satellite, Royer et al. [1988] found that the predominantly used atmospheric radiative transfer codes tend to disagree significantly only at large aerosol optical thicknesses.

Retrievals of $\omega_{0}$ with the SPCTRAL2 model, utilizing broadband PAR irradiance measurements, for the tropical forest region of Jamari in Rondonia are shown in Figure 9a. The data shown are for the cloudless periods of four consecutive days with very high aerosol loadings, September 4-7, 1995 (days 247-250), with $\tau_{2441}$ ranging from 1.6 to 4.5 (Figure 9b). The Angstrom wavelength exponent shows very little variation over this 4 day period, ranging from about 1.7 to 1.9 . The values of $\omega_{\mathrm{n}}$ inferred ranged from about 0.85 to 0.91 , with differences in $\omega_{\mathrm{a}}$ of only about 0.005 to 0.01 resulting from a change in assumed surface reflectance of soil or vegetation. 

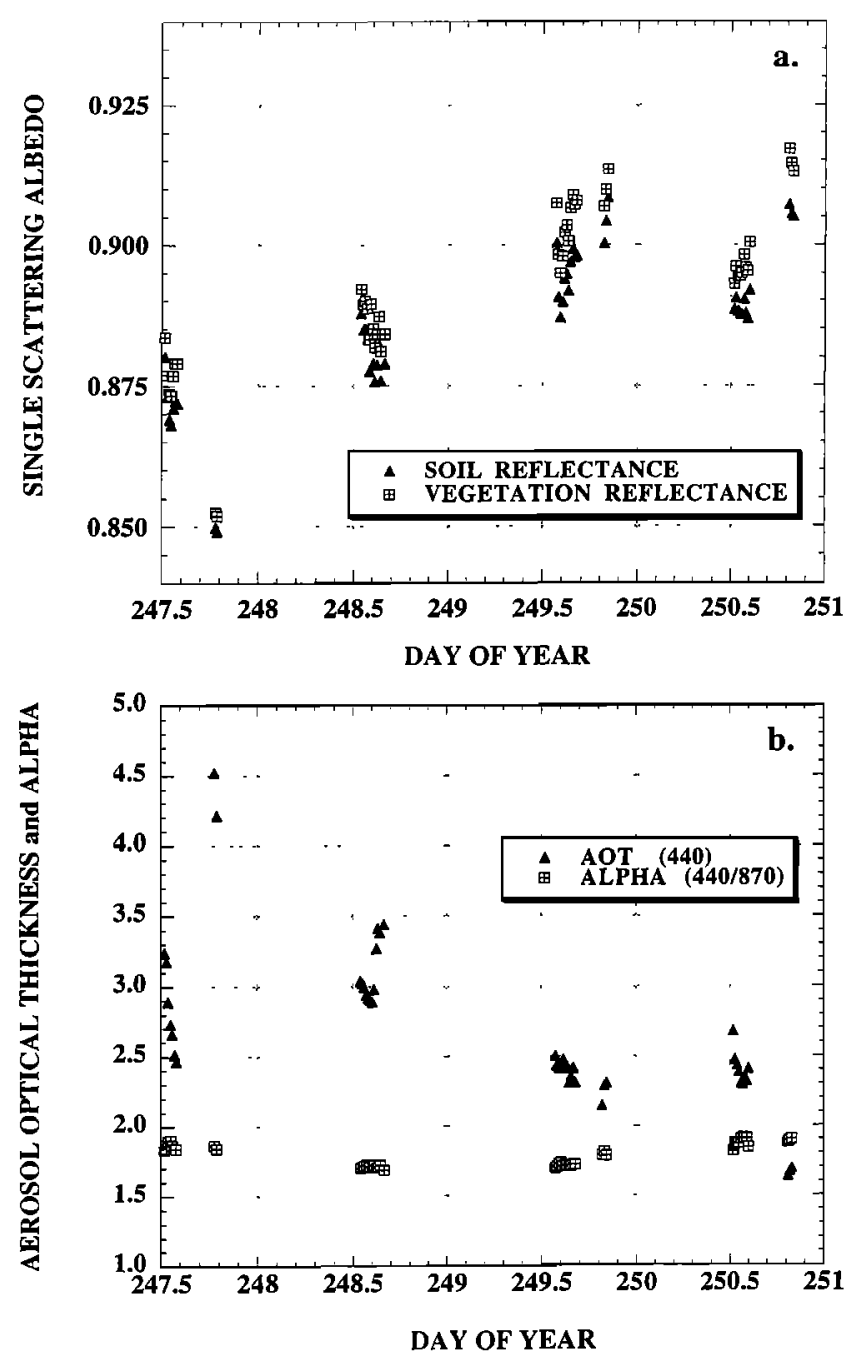

Figure 9. (a) Retrievals of $\omega_{\mathrm{o}}$ for Potosi Mine, Rondonia, near Jamari from September 4-7, 1995, utilizing the SPCTRAL2 model and measured broadband PAR $(400-700 \mathrm{~nm})$ irradiances (b) Extremely high aerosol optical thickness for this 4 day period, ranging from 1.6 to 4.5 at $440 \mathrm{~nm}$, with Angstrom wavelength exponent (alpha) remaining very stable from 1.7 to 1.9 .

The value of the asymmetry parameter $(\mathrm{g})$ assumed here was 0.58 , and the sensitivity to this value was relatively small, with $\omega_{0}$ retrievals decreasing by about 0.01 for an assumed $\mathrm{g}=$ 0.65 . The lowest values of $\omega_{n}, 0.85$, occurred for the case of the highest $\tau_{\mathrm{s} 440}$ on the afternoon of September 4 (day 247), when a very dense aerosol cloud was advected into the area. This very dense aerosol cloud was possibly from recent and active burning taking place upwind of the site. The values of $\omega_{\mathrm{o}}$ inferred from the $6 \mathrm{~S}$ model for September 6 and 7 at this site were about 0.03 to 0.05 higher than the SPCTRAL2 model values shown here (see Table 1, the Rondonia case for September 6, 1995).

The values of $\omega_{0}$ which we have retrieved with the above techniques fall within the range of values previously reported for biomass burning smoke. For example, Radke et al. [1991] measured an average $\omega_{0}$ at visible wavelengths of 0.83 for plumes of several North American temperate zone prescribed fires and wildfires, with most values in the range 0.80 to 0.90 .
For biomass burning fires in the Amazon basin, Kaufman et al. [1992] computed the $\omega_{0}$ to be $0.90+0.01$ (wavelength not reported), assuming graphitic carbon in an external mode mixture. Horvath [1993] also computed a value of 0.90 for $\omega_{n}$ (wavelength not reported) of biomass burning aerosols in Amazonia based on the measurements of aerosol composition of Andreae et al. [1988]. Reid et al. [this issue] present the results of many aircraft-based in situ measurements of regional smoke haze in Amazonia utilizing four different techniques, which show $\omega_{0}$ ranging from 0.80 to 0.90 at $550 \mathrm{~nm}$. A comparison between these in situ based methods and the ground based remote sensing technique presented here was done for three separate cases during SCAR-B [Reid et al., this issue]. This comparison showed the $\omega_{0}$ values retrieved with the SPCTRAL2 model to be in excellent agreement with the in situ techniques (within about 0.01 ) and the retrievals of $\omega_{0}$ from $6 S$ to be in excellent agreement with in situ determinations for a case of moderate aerosol loading, and values inferred for very high aerosol loadings $\left(\tau_{\mathrm{a} 5(\mathfrak{k})}=2.08\right)$ from $6 S$ to be higher by approximately 0.02 to 0.05 .

For two prescribed fires, Radke et al. [1991] measured the $\omega_{i,}$ to be under 0.7 for the flaming phase of the fires compared to a value of approximately 0.90 for the smoldering phase. Under laboratory conditions, Patterson and McMahon [1984] observed much higher rates of elemental carbon produced in the flaming phase relative to the smoldering phase. Therefore the lower $\omega_{n}$ values which we measured in the Cuiaba region may be due to the greater production of smoke from flaming phase combustion in cerrado fires, versus the higher values of $\omega_{0}$ in Potosi Mine, Rondonia, which is in a region of tropical forest conversion to agriculture. The felled trees which are subsequently burned in these areas tend to smolder for a long period of time after the flaming phase ends. The ratio of smoke production from flaming verus smoldering phases in part determines the amount of black carbon in the aerosol and thus directly influences the absorption properties and $\omega_{n}$ of the fresh smoke. There may be many other processes at work, however, in the evolution of the $\omega_{11}$ with time, including absorption of water by the aerosols, gas to particle conversion, coagulation of aerosols into larger particles, and cloud processing of aerosols possibly modifying the aerosol size distribution and their absorption properties with aging [Radke et al., 1991].

\section{Biomass Burning Season Estimates of PAR Irradiance Attenuation}

In order to assess the impact of the biomass burning smoke aerosols on the attenuation of PAR irradiance for the peak burning season (August-September), we computed the irradiance based on aerosol optical depths measured by Sunsky scanning radiometers which were located at four sites within Amazonia (Table 2). The SPCTRAL2 model was used to calculate the ratio of irradiance computed with measured $\tau_{d}$ versus the background (preburning season) values of $\tau_{\mathrm{u}}$. Measured aerosol optical depths at wavelengths of 339,437 , 498,669 , and $871 \mathrm{~nm}$ were input to the SPCTRAL2 model. The value of the asymmetry parameter which was assumed for the burning season at all sites was 0.58 , which is based on almucantar retrievals made at $\tau_{\mathrm{i} 440}$ of approximately 1.0 in Amazonia. Values of $\omega_{0}$ assumed for the burning season were based on retrievals made with the SPCTRAL2 model and 
Table 2. Computed Reduction in PAR (400-700 nm) Irradiance During the Biomass Burning Season Resulting From Attenuation by Aerosols

\begin{tabular}{|c|c|c|c|c|}
\hline Location & Dates & Average $\tau_{\mathrm{u} 500}$ & Assumed $\omega_{0}$ & $\begin{array}{l}\% \text { PAR } \\
\text { Reduction }\end{array}$ \\
\hline $\begin{array}{l}\text { Ji-Parana } \\
\text { Rondonia, Brazil } \\
10.85^{\circ} \mathrm{S}, 61.78^{\circ} \mathrm{W}\end{array}$ & $\begin{array}{l}\text { Aug. 19-Sept. 30, } \\
1995 \\
43 \text { days }\end{array}$ & 2.14 & $\begin{array}{l}0.85 \\
0.90\end{array}$ & $\begin{array}{l}45 \\
38\end{array}$ \\
\hline \multirow[t]{2}{*}{$\begin{array}{l}\text { Alta Floresta } \\
\text { Mato Grosso, Brazil } \\
9.92^{\circ} \mathrm{S}, 56.00^{\prime \prime} \mathrm{W}\end{array}$} & $\begin{array}{l}\text { Aug. 5-Sept. 30, } \\
1995 \\
57 \text { days }\end{array}$ & 1.61 & $\begin{array}{l}0.85 \\
0.90\end{array}$ & $\begin{array}{l}36 \\
30\end{array}$ \\
\hline & $\begin{array}{l}\text { Aug. 1-Sept. 28, } \\
1994 \\
59 \text { days }\end{array}$ & 1.33 & $\begin{array}{l}0.85 \\
0.90\end{array}$ & $\begin{array}{l}33 \\
27\end{array}$ \\
\hline \multirow[t]{3}{*}{$\begin{array}{l}\text { Cuiaba } \\
\text { Mato Grosso, Brazil } \\
15.50^{\circ} \mathrm{S}, 56.00^{\circ} \mathrm{W}\end{array}$} & $\begin{array}{l}\text { Aug. 1-Sept. 30, } \\
\text { 1995 } \\
\text { 61 days }\end{array}$ & 0.94 & $\begin{array}{l}0.80 \\
0.85 \\
0.90\end{array}$ & $\begin{array}{l}27 \\
23 \\
20\end{array}$ \\
\hline & $\begin{array}{l}\text { Aug. 13-Sept. } 29 \text {, } \\
1994 \\
48 \text { days }\end{array}$ & 1.08 & $\begin{array}{l}0.80 \\
0.85 \\
0.90\end{array}$ & $\begin{array}{l}32 \\
28 \\
23\end{array}$ \\
\hline & $\begin{array}{l}\text { Aug. 2-Sept. 27, } \\
1993 \\
56 \text { days }\end{array}$ & 1.08 & $\begin{array}{l}0.80 \\
0.85 \\
0.90\end{array}$ & $\begin{array}{l}31 \\
27 \\
23\end{array}$ \\
\hline $\begin{array}{l}\text { El Refugio } \\
\text { Bolivia } \\
14.75^{\circ} \mathrm{S}, 62.03^{\circ} \mathrm{W}\end{array}$ & $\begin{array}{l}\text { Aug. } 15-29 \\
1995 \\
15 \text { days }\end{array}$ & 1.35 & $\begin{array}{l}0.85 \\
0.90\end{array}$ & $\begin{array}{l}33 \\
28\end{array}$ \\
\hline
\end{tabular}

SPCTRAL2 model calculations of percent PAR reductions are integrations over the entire time periods with values of assumed $\omega_{0}$.

described in the previous section. The preburnıng season aerosol optical properties were assumed the same for all sites with $\tau_{\mathrm{asN}(0)}=0.15$ and Angstrom wavelength exponent of 1.10 based on the measurements of Holben et al. [1996], and assumed values of $\omega_{0}=0.945$ and $g=0.65$. As was shown in Figure 4 , the $\omega_{\mathrm{o}}$ value does not have a large influence on irradiance at these low preburning season aerosol loadings. The daily integrated totals of irradiance based on the measured $\tau_{\mathrm{a}}$ within the burning season were computed for all days within the time period, and the sum ratioed to the sum of daily integrals computed for the background, preburning season aerosol conditions. The length of the time period analyzed at each site and year varied from 15 days to 61 days and is not the length of the biomass burning season at each site, but the length of the data record available during August-September when the Sun-sky scanning radiometer was operational.

The sites of Ji-Parana, Rondonia and Alta Floresta, Mato Grosso, are located in tropical forest regions of Amazonia (Figure 1) and are also in major regions of agricultural activity and thus biomass burning. Therefore these sites would be representative of levels of aerosol loading which would approach the maximum for burning regions within the Amazon Basin. The largest reductions in PAR were computed for $\mathrm{Ji}$ Parana in 1995, which was a dry year [Mattos et al., 1996] and thus a year with more intense and prolonged burning than a typical year. The average $\tau_{\alpha 500}$ at this site for the 43 days of data availability was 2.14 , which is very high, and the resultant computed reduction in PAR irradiance (compared to preburning season aerosol conditions) ranged from $38 \%$ to
$45 \%$ for assumed $\omega_{0}$ values of 0.90 and 0.85 , respectively (Table 2). For Alta Floresta in 1995, the seasonal average $\tau_{\mathrm{n} 50 \%}$ is not as high, at 1.61 for a 57 day period, and the resultant computed reductions in PAR irradiance range from $30 \%$ to $36 \%$ for $\omega_{0}$ values of 0.90 and 0.85 , respectively. Alta Floresta in 1994 shows lower average aerosol optical depth $\left(\tau_{a 500}=1.33\right)$ than in 1995 and therefore lesser reductions in PAR irradiance, ranging from $27 \%$ to $33 \%$ for $\omega_{0}$ of 0.90 and 0.85 , respectively. Calculations were made for three years, 19931995, for Cuiaba, which is located in a cerrado biomass burning region and which also is affected by biomass burning smoke which is advected from forest burning areas to the north such as the Alta Foresta region. The burning season average $\tau_{\mathrm{u}}$ did not change very much from year to year during this period, ranging from 0.94 in 1995 to 1.08 in both 1994 and 1993. Calculations of reductions in PAR irradiance were made with the $\omega_{0}$ value of 0.80 in addition to 0.85 and 0.90 , since retrievals of $\omega_{0}$ in the previous section showed lower values for this site, which may be the result of a greater proportion of flaming phase combustion and higher black carbon content in the aerosol from cerrado burning. The resultant estimated reductions in PAR irradiance at Cuiaba ranged from $20 \%$ to $32 \%$ dependent mainly on the assumed value of $\omega_{0}$ with the most likely reductions ranging from $23 \%$ to $28 \%$, associated with a $\omega_{0}$ value of 0.85 . Even locations which have very little local biomass burning may experience significant reductions in PAR irradiance due to advection of smoke from adjacent regions of biomass burning. For example, El Refugio, Bolivia is located within Noel Kempf Mercado National Park, which is 


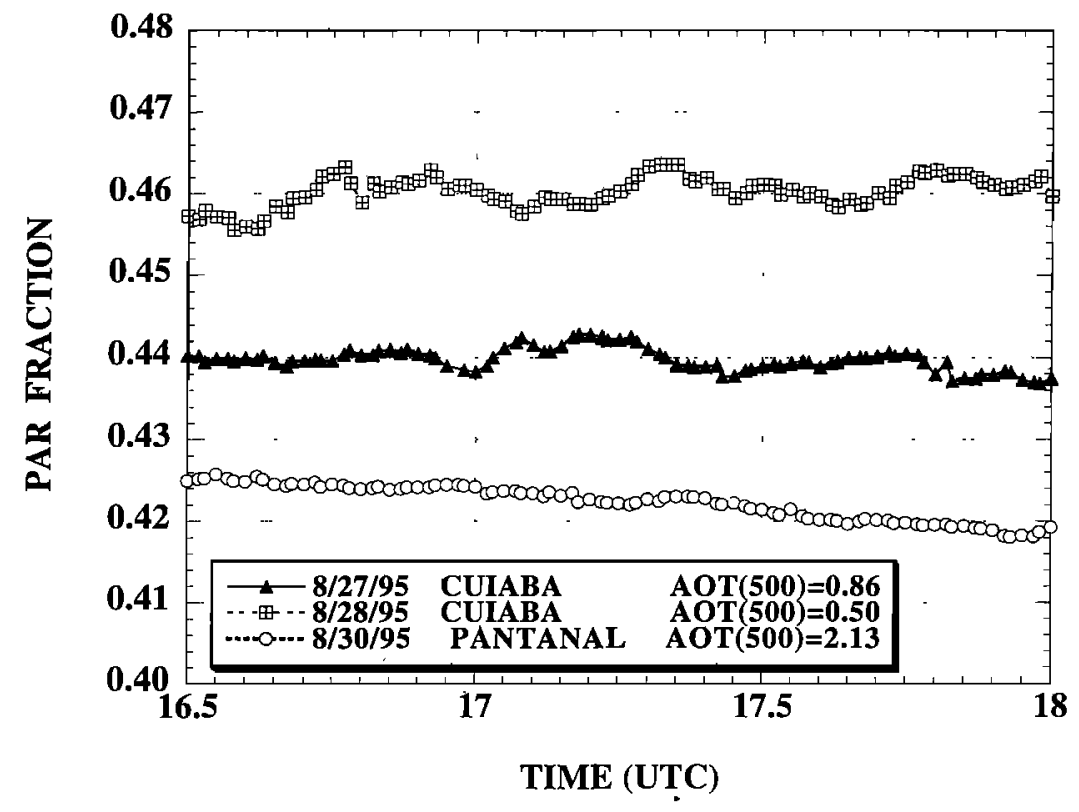

Figure 10. Measured PAR fraction, or the ratio of PAR $(400-700 \mathrm{~nm})$ irradiance, to "total" $(280-2800 \mathrm{~nm})$ irradiance for three cases of varying aerosol optical thickness (AOT) in Cuiaba and northern Pantanal (world's largest wetland).

an extensive protected region with little burning, yet smoke is advected here from Rondonia, Brazil and biomass burning regions within Bolivia. For 15 days in August 1995 when a Sun-sky scanning radiometer was operational at the site, there was a measured average $\tau_{\mathrm{is}\left(x_{\mathrm{x}}\right)}=1.35$, which resulted in PAR irradiance reductions estimated to be from $28 \%$ to $33 \%$ for $\omega_{0}$ values of 0.90 and 0.85 , respectively.

For all of the above calculations of PAR irradiance reduction, due to attenuation by biomass burning aerosols. the model calculations are valid for cloudless sky conditions. Since the sky is not always cloudless in the dry season in these regions of southern Amazonia, these calculations for cloudless conditions will differ from the actual reductions in irradiance. Computing the effects on irradiance of combined cloud and aerosol effects is beyond the scope of this paper. However, the authors have often observed relatively low cloud fractions while taking measurements in these regions of heavy aerosol loading in the Amazonian dry season (August-September). Moreover, reductions in surface incident solar radiation from absorbing aerosols in conjunction with absorption within the aerosol layer may result in a reduction of local cloud cover, which Hansen et al. [1997] call the "semidirect" aerosol radiative forcing effect.

\section{Aerosol Effects on the Fraction of PAR to Total Irradiance}

The fraction of PAR $(400-700 \mathrm{~nm})$ to total $(280-2800 \mathrm{~nm})$ irradiance as measured by the combination of Skye-Probetech PAR sensors and Eppley PSP pyranometers is shown in Figure 10 for a solar zenith angle range of about $28^{\prime \prime}$ to $42^{\circ}$. Measurements were made within a 4 day period in Cuiaba and northern Pantanal (about $100 \mathrm{~km} \mathrm{SSW}$ of Cuiaba) with differing levels of aerosol loading, with $\tau_{\text {s5in }}$ ranging from 0.50 to 2.13 . The PAR fraction ranged from about 0.46 at $\tau_{\mathrm{a} 500}$ $=0.50$ to about 0.42 at $\tau_{\mathrm{as}(\mathrm{K})}=2.13$. In comparison, Pinker and
Laszlo [1992] computed the PAR faction reduction from 0.45 to 0.42 , for a range of aerosol optical depth from 0.0 to 1.2 , for a continental aerosol model. The magnitude of the PAR fraction reduction with increases in $\tau_{d}$ depends also on the value of $\omega_{1}$ and asymmetry parameter, both of which exhibit wavelength dependence. The reduction of UV irradiance (300$400 \mathrm{~nm}$ ) is greater than that for PAR irradiance (Figure 3), due to higher $\tau_{d}$ at UV wavelengths, while the reduction in near infrared irradiance is less than that for the PAR reduction due to lower $\tau_{s}$ as wavelength increases (Figures 2 and 3 ). However, from the measured PAR fractions shown in Figure 10, we can infer that the total irradiance reduction is also high, although lower than PAR reduction, for cases of high aerosol loading. For example, assuming a PAR fraction of 0.46 for background conditions and 0.42 for high aerosol loading, and an assumed $40 \%$ reduction (compared to background conditions) in PAR irradiance at $\tau_{a 500}=2.13$, we can estimate that the reduction in total irradiance is about $34 \%$. Of course, this is a general estimate which would be modified for differing values of the wavelength dependence of $\omega_{n}$ and $\mathrm{g}$. This case would be similar to the aerosol loading measured at Ji-Parana in 1995 for 43 days in August-September with the resulting computed PAR reduction of $38-45 \%$ (Table 2 ).

\section{Summary and Conclusions}

Measurements of both broadband and spectral irradiance in Amazonia were used in conjuction with measured aerosol optical properties ( $t_{\iota}, \mathrm{g}$, and aerosol size distributions) to retrieve values of single scattering albedo $\left(\omega_{10}\right)$ for biomass burning aerosols. Irradiance under cloudless sky conditions is very sensitive to the magnitude of aerosol absorption and therefore $\omega_{0}$ for cases of middle to high aerosol loading, which frequently occur in biomass burning regions of Amazonia during August-September. Retrievals of $\omega_{n}$ using broadband PAR $(400-700 \mathrm{~nm})$ irradiance measurements in conjuction with 
measured aerosol optical properties and cloudless sky irradiance models yielded $\omega_{0}$ values which ranged from 0.81 to 0.94, using two different irradiance models. Agreement between the $\omega_{0}$ retrievals using the SPCTRAL2 and 6S models was good for aerosol loading corresponding to $\tau_{45 \times 1}$ of 0.9 to 1.3 , while for very high aerosol loadings $\left(\tau_{\mathrm{aSkx}}=2.1\right)$ the $6 \mathrm{~S}$ model retrievals of $\omega_{n}$ were 0.02 to 0.05 higher than SPCTRAL2 retrievals. The $6 S$ model retievals of $\omega_{10}$ depend in part on the assumed real part of the refractive index and the aerosol size distribution and associated modal particle radius. For two different days on which spectral irradiance data were available, both models retrieved a similar magnitude of $\omega_{0}$ decrease with increasing wavelength, with the magnitude of the decrease in wavelength differing on these 2 days.

Reductions in PAR irradiance at the surface were computed for cloudless conditions for the burning season months of August-September at sites located in biomass burning regions in Amazonia. Measurements of aerosol optical depth made with automatic Sun and sky scanning radiometers were input to the SPCTRAL2 model along with a range of $\omega_{n}$ values representative of the region, based on previous retrievals. These computations show large reductions in PAR irradiance for cloudless skies over the 2 month burning season, ranging from 20 to $45 \%$, dependent on the aerosol optical depth at the site and the value of $\omega_{0}$. Due to long-range transport of biomass burning aerosols, even areas which do not experience local burning may be impacted by the radiative effects of high smoke aerosol loading. Ecologically significant and sensitive regions of Amazonia and the Pantanal are subjected to events with large aerosol optical depth.

Gash and Nobre [1997] have suggested that rainforest clearing, in regions with large cleared areas such as in Rondonia, Brazil, may increase local cloud cover through differential surface heating and resultant mesoscale circulations with a deeper mixed layer over the cleared area. They suggest that this may result in increased cloud cover over the cleared area. The results of our analysis presented here show significant reductions in surface irradiance and therefore likely reductions in surface heating which result from smoke aerosols. It also follows that as a result of the absorbing nature of the aerosols there would likely be an increase in heating within the mixed layer, leading to increased atmospheric stability. Therefore during the burning season months of August-September the aerosol radiative effects may act to suppress convection and therefore may decrease local cloud cover.

Acknowledgments. This project was supported by Diane Wickland, NASA Headquarters, and Mike King, EOS Project Science Office. We gratefully acknowledge the assistance of Joe Vaughan (Washington State University) in field experiment participation during SCAR-B, and in providing us the data from his MFRSR shadowband radiometer located in Cuiaba during the experiment. We also thank Alfreido Periera and Jose Chagas (INPE) for setting up Sun and sky scanning radiometers at field sites in Brazil and in assisting in experiment logistics. We are indebted to the efforts of several site managers, who maintained instruments in several locations in Brazil and Bolivia. These include Santurnino in Alta Floresta, Brazil; Levi in Ji-Parana, Brazil; and Tim Killeen (Missouri Botanical Gardens) in El Refugıo, Bolivia. We also thank the reviewers for their thoughtful comments, which helped in improving the manuscript.

\section{References}

Anderson, B.E., W.B. Grant, G.L. Gregory, E.V. Browell, J.E., Collins, Jr., G.W. Sachse, D.R. Bagwell, C.H. Hudgins, D.R. Blake, and N.J.
Blake, Aerosols from biomass burning over the tropical South Atlantic region: Distributions and impacts, J. Geophys. Res., 101, 24,11724,137, 1996.

Andreae, M.O., et al., Biomass-burning emissions and associated haze layers over Amazonia, J. Gerophys. Res., 93, 1,509-1,527, 1988.

Artaxo, P., F. Gerab, M.A. Yamasoe, and J.V. Martins, Fine mode aerosol composition at three long-term atmospheric monitoring sites in the Amazon Basin, J. Geophys. Res., 99, 22,857-22,868, 1994.

Bird, R.E., and C. Riordan, Simple solar spectral model for direct and diffuse irradiance on horizontal and tilted planes at the Earth's surface for cloudless atmospheres, J. Clim. Appl. Meteorsl., 25, 87 97, 1986.

Christopher, S.A., D.V. Kliche, J. Chou, and R.M. Welch, First estimates of the radiative forcing of aerosols generated from biomass burning using satellite data, J. Geophys. Res., 101, 21,265-21,273, 1996.

Deering, D.W., Field Measurements of bidirectional reflectance, in Theory and Applications of Optical Remote Sensing, edited by G. Asrar, chap. 2, John Wiley, New York, 1989.

Gash, J.H.C., and C.A. Nobre, Climatic effects of Amazonian deforestation: Some results from ABRACOS, Bull. Am. Meteorol. Soc.. 78, 823-830, 1997.

Hansen, J., M. Sato, and R. Ruedy, Radiative forcing and climate response, J. Geophys. Res., 102, 6,831-6,864, 1997.

Hobbs, P.V., J. S. Reid, R. A. Kotchenruther, R.J. Ferek, and R. Weiss, Direct radiative forcing by smoke from biomass burning, Science. $275,1,776-1,778,1997$.

Holben, B.N., A. Setzer, T.F. Eck, A. Pereira, and I. Slutsker, Effect of dry season biomass burning on Amazon basin aerosol concentrations and optical properties, J. Geophys. Res., 101, 19,465-19,481, 1996.

Holben, B.N., et al., AERONET - A Federated instrument network and data archive for aerosol characterization, Remote Sens. Environ., in press, 1998.

Horvath, H., Atmospheric light absorption-A review, Atmos. Environ., 27A, 293-317, 1993.

Hsu, N.C., J.R. Herman, P.K. Bhartia, C.J. Seftor, O. Torres, A.M. Thompson, J.F. Gleason, T.F. Eck, and B.N. Holben, Detection of biomass burning smoke from TOMS measurements, Geophys. Res. Lett., 23, 745-748, 1996.

Ji, Q., S.-C. Tsay, Y.J. Kaufman, and G.E. Shaw, SCAR-B ground-based measurements of aerosol microphysics in Cuiaba, in Smoke. Clouds, and Radiation-Brazll: Proceeding.s, edited by V.W.J.H. Kurchhoff, pp. 79-83, Transtec Editorial, Sao Jose dos Campos, Brazil, 1996.

Kaufman, Y.J., A. Setzer, D. Ward, D. Tanre, B.N. Holben, P. Menzel, MC. Pereira, and R. Rasmussen, Biomass burning airborne and spaceborne experiment in the Amazonas (BASE-A), J. Geophys. Res., 97, 14,581-14,599, 1992.

Konzelmann, T., D.R. Cahoon, and C.H. Whitlock, Impact of biomass burning in equatorial Africa on the downward surface shortwave solar irradiance: Observations versus calculations, J. Geophys. Res., 101, 22,833-22,844, 1996.

Lenoble, J., The particulate matter from biomass burning: A tutorial and critical review of its radiative impact, in Global Biomass Burning: Atmospheric, Climatic, and Biospheric Implications, edited by J.S. Levine, pp. 381-386, MIT Press, Cambridge, Mass., 1991.

Martins, J.V., P.V. Hobbs, R.E. Weiss, and P. Artaxo, Shapes of smoke particles from biomass burning in Brazil, in Smoke, Clouds, and Radiation-Brazil: Proceedings, edited by V.W.J.H. Kirchhoff, pp. 141-144, Transtec Editonal, Sao Jose dos Campus, Brazil, 1996.

Mattos, L.F., C.P. Dereczynski, T.A. Tarasova, I.V. Trosnıkov, and C.A. Nobre, Brazilian contribution to SCAR-B Project-Meteorology, in Smoke, Clouds, and Radiation-Brazil: Proceedings, edited by V.W.J.H. Kirchhoff, pp. 145-148, Transtec Editorial, Sao Jose dos Campus, Brazil, 1996.

Nakajima, T., M. Tanaka, and T. Yannauchi, Retrieval of the optical properties of aerosols from aureole and extinction data, Appl. Opt., $22,2,951-2,959,1983$.

Nakajima, T., T. Glauco, R. Rao, P. Boi, Y. J. Kaufman, and B.N. Holben, Use of sky brightness measurements from ground for remote sensing of particulate polydispersions, Appl. Opt., 35, 2,672-2,686, 1996.

Neckel, H., and D. Labs, Improved data of solar spectral irradiance from 0.33 to $1.25 \mu \mathrm{m}$, Solar Phys., 74, 231-249, 1981.

Patterson, E.M., and C.K. McMahon, Absorption characterisitcs of forest fire particulate matter, Atmos. Environ., 18, 2,541-2,551, 1984.

Penner, J.E., R.E. Dickinson, and C.A. O'Neill, Effects of aerosol from biomass burning on the global radiation budget, Science, 256, 1,4321,433, 1992. 
Pinker, R.T., and I. Laszlo, Global distribution of photosynthetically active radiation as observed from satellite, J. Clim., 5, 56-65, 1992.

Prins, E.M., and W.P. Menzel, Trends in South American biomass burning detected with the GOES visible infrared spin scan radiometer atmospheric sounder from 1983 to 1991, J. Geophys. Res., 99, $16,719-16,735,1994$.

Radke, L.F., D.A. Hegg, P.V. Hobbs, J.D. Nance, J.H. Lyons, K.K. Laursen, R.E. Weiss, P.J. Riggan, and D.E. Ward, Particulate and trace gas emissions from large biomass fires in North America, in Global Biomass Burning: Atmospheric Climatic, and Biospheric Implications, edited by J.S. Levine, pp. 209-224, MIT Press, Cambridge, Mass., 1991.

Reid, J.S., P.V. Hobbs, C. Liousse, J.V. Martins, R.E. Weiss, and T.F. Eck, Comparisons of techniques for measuring shortwave absorption and black carbon content of aerosols from biomass burning in Brazil, J. Geophys. Res., this issue.

Remer, L.A., Y. Kaufman, B.N. Holben, A.M. Thompson, and D.P. McNamara, Biomass burning aerosol size distribution and modeled optical properties, J. Geophys. Res., this issue.

Robock, A., Surface cooling due to forest fire smoke, J. Geophys. Res., $96,20,869-20,878,1991$.

Royer, A., N.T. O'Neill, A. Davis, and L. Hubert, Comparison of radiative transfer models used to determine atmospheric optical parameters from space, Proc. SPIE Int. Soc. Opt. Eng., 928, 118-135, 1988.
Shaw, G.E., Sun photometry, Bull. Am. Meteorol. Soc.. 64, 4-10, 1983.

Skole, D., and C. Tucker, Tropical deforestation and habitat fragmentation in the Amazon: Satellite data from 1978 to 1988 , Science, 260, 1905-1910, 1993.

Vermote, E., D. Tanre, J.L. Deuze, M. Herman, and J.J. Morcrette, Second Simulation of the Satellite Signal in the Solar Spectrum (6S), 6S Users Guide Version I, Jan. 1996.

Vermote, E., D. Tanre, J.L. Deuze, M. Herman, and J.J. Morcrette, Second Simulation of the Satellite Signal in the Solar Spectrum, 6S: An overview, IEEE Trans. Geosci. Remote Sens., 35, 675-686, 1997.

T.F. Eck, Raytheon STX Corporation, Code 923, NASA/Goddard Space Flight Center, Greenbelt, MD 20771. (email:tom@spamer.gsfc.nasa.gov)

B.N. Holben, Biospheric Sciences Branch, Code 923, NASA/Goddard Space Flight Center, Greenbelt, MD 20771. (email:brent@spamer.gsfc.nasa.gov)

A. Setzer, Instituto de Pesquisas Espacias, Sao Jose dos Campos, Sao Paulo, Brazil 12201-970. (e-mail:asetzer@ltid.inpe.br)

I. Slutsker, Science Systems and Applications Inc., Code 923, NASA/Goddard Space Flight Center, Greenbelt, MD 20771. (e-mail: ilya@spamer.gsfc.nasa.gov)

(Recieved August 15, 1997; revised January 16, 1998; accepted January 29, 1998.) 